Research Article

\title{
Removal of Methylene Blue Dye from Wastewater Using Periodiated Modified Nanocellulose
}

\author{
Hizkeal Tsade Kara $\mathbb{D}^{1},{ }^{1}$ Sisay Tadesse Anshebo $\mathbb{D}^{\mathbb{D}},{ }^{2}$ Fedlu Kedir Sabir $\mathbb{D}^{1},{ }^{1}$ \\ and Getachew Adam Workineh ${ }^{3}$ \\ ${ }^{1}$ Department of Applied Chemistry, School of Applied Natural Science, Adama Science and Technology University, P.O. Box 1888, \\ Adama, Ethiopia \\ ${ }^{2}$ Department of Chemistry, College of Natural and Computational Sciences, Hawassa University, Hawassa, P.O. Box 05, Ethiopia \\ ${ }^{3}$ Department of Industrial Chemistry, College of Applied Science, Addis Ababa Science and Technology University, \\ P.O. Box 16417, Addis Ababa, Ethiopia
}

Correspondence should be addressed to Hizkeal Tsade Kara; hizts4@gmail.com

Received 6 March 2021; Revised 24 April 2021; Accepted 8 June 2021; Published 17 June 2021

Academic Editor: Mulugeta Admasu Delele

Copyright (c) 2021 Hizkeal Tsade Kara et al. This is an open access article distributed under the Creative Commons Attribution License, which permits unrestricted use, distribution, and reproduction in any medium, provided the original work is properly cited.

\begin{abstract}
The study was focused on the preparation and characterizations of sodium periodate-modified nanocellulose $\left(\mathrm{NaIO}_{4}-\mathrm{NC}\right)$ prepared from Eichhornia crassipes for the removal of cationic methylene blue (MB) dye from wastewater (WW). A chemical method was used for the preparation of $\mathrm{NaIO}_{4}-\mathrm{NC}$. The prepared $\mathrm{NaIO}_{4}-\mathrm{NC}$ adsorbent was characterized by using X-ray diffraction (XRD), Fourier transform infrared (FTIR), scanning electron microscope (SEM), energy-dispersive X-ray (EDX), and Brunauer-Emmett-Teller (BET) instruments. Next, it was tested to the adsorption of MB dye from WW using batch experiments. The adsorption process was performed using Langmuir and Freundlich isotherm models with maximum adsorption efficiency $\left(q_{\max }\right)$ of $90.91 \mathrm{mg} \cdot \mathrm{g}^{-1}$ and percent color removal of $78.1 \%$ at optimum $30 \mathrm{mg} \cdot \mathrm{L}^{-1}, 60 \mathrm{~min} ., 1 \mathrm{~g}$, and 8 values of initial concentration, contact time, adsorbent dose, and solution $\mathrm{pH}$, respectively. Pseudo-second-order (PSO) kinetic model was well fitted for the adsorption of MB dye through the chemisorption process. The adsorption process was spontaneous and feasible from the thermodynamic study because the Gibbs free energy value was negative. After adsorption, the decreased values for physicochemical parameters of WW were observed in addition to the color removal. From the regeneration study, it is possible to conclude that $\mathrm{NaIO}_{4}-\mathrm{NC}$ adsorbent was recyclable and reused as $\mathrm{MB}$ dye adsorption for 13 successive cycles without significant efficient loss.
\end{abstract}

\section{Introduction}

Textile industries have been a major contributor to the world economy. Conversely, pollution level from dyes is increasing and maintainability issues should be considered at each point of the source level. The majority of dyeing manufacturing industries have a high contaminating footprint, and it is estimated that up to 200,000 tons of dyes are discharged into water bodies because of inefficient wastewater treatment processes [1]. Methylene blue (MB) (3,7bis(dimethylamino)-phenothiazin-5-ium chloride) is a thiazine cationic dye that is extensively used to dye textiles, such as cotton, cellulose, wood, and silk [2]. Despite the valuable uses of $\mathrm{MB}$ in science, the dye has harmful effects on humans and the environment because of its water solubility. It is noxious, a mutagenic reagent and is supposed to be a cancer-causing dye [3]. Furthermore, MB is possibly harmful to human health and contributes to causing chronic toxicity [4], predominantly to the central nervous system [5]. The effluent produced from the textile industry is seriously colored, encompasses high concentrations of salts, and shows high biological oxygen demand/chemical oxygen demand values. Thus, there is a crucial requirement to remove $\mathrm{MB}$ for an improved and cleaner environment and health [6].

A number of WW treatment technologies were investigated for the removal of MB dyes, such as adsorption, 
photocatalysis, ion exchange, electrochemical, oxidationreduction, and catalytic processes [7-11]. Among the abovestated dye removal technologies, adsorption appears the most economical method because of its inexpensiveness, easy working principle, and high pollutant uptake capacities [12]. Most industrial activities normally use activated carbon as an adsorbing reagent due to its high absorbency and specific surface area [13]. Activated carbon obtained from the market is expensive because of its high production cost for regeneration purposes [14]. Currently, the idea of the use of nanomaterials as adsorbing reagents is increasing [15]. However, nanomaterials, such as titania nanotube, carbon nanotube, and nano zerovalent iron, are toxic and not suitable for dye removal [16]. These limitations were easily solved by preparing the nanomaterials from cellulose-based sources such as wheat straw [17], wood [18], waste paper [19], and agroforestry residues [20]. Cellulose-based adsorbent materials are considered low-cost, easily available, biodegradable, and nontoxic materials for the removal of contaminants in general and cationic MB dye in particular from WW [21].

Therefore, preparing innovative, easily available, and nontoxic adsorbent materials with high uptake capabilities is a current world issue for the removal of dyes from the WW [22]. Nanocellulose (NC) is a natural porous lignocellulosic biomass; one of its dimensions is in the nanoscale range, being abundantly available in the environment and fairly cheap. Depending on the source materials and preparation methods, NC is classified into nanocrystalline celluloses (NCCs), nanofibrillated celluloses (NFCs), and bacterial nanocelluloses (BNCs). This study focuses on the preparation, characterization, and application of NCCs for cationic MB dye removals. The NCC adsorbent was prepared by sulfuric hydrolysis methods. It is testified to be harder than steel [23] and more operative for the removal of cationic $\mathrm{MB}$ dye. However, the unique characteristics it had shown are of relatively low efficiency and need surface modification to enhance the uptake capabilities. Therefore, to increase the specific surface area and mechanical properties of NCC, surface modification has been attempted. Esterification [24], acetylation [25], fluorination [26], and silanization [27] are the common methods for modifying the NCC surfaces. However, such chemical modification methods of NCC mostly performed in a nonaqueous organic solvent method and required a long time. So, the subsequent surfacemodified NCC loses its inherent environment, which reduces its stable contaminant uptake in an aqueous media. Thus, the periodate oxidation process can be used instead to modify NCC by introducing two aldehyde groups at $\mathrm{C}_{2}$ and $\mathrm{C}_{3}$ with concomitant $\mathrm{C}_{2}-\mathrm{C}_{3}$ bond cleavage $[28,29]$. This simple one-pot method only requires water and sodium periodate as a solvent and an oxidation reagent, respectively. This oxidation process is relatively simple and takes a very short time to complete the reaction.

Furthermore, many of NCCs used for dye removal were prepared from different sources, including wood, agroforestry, and waste paper; however, to the best of the authors' knowledge, a few studies have been reported on NCCs prepared from aquatic weed Eichhornia crassipes. In addition to this, these materials do not have negative economic effect on the societies and extra cost is needed remove them from water bodies. Therefore, the aim of this study was to remove cationic methylene blue (MB) dye from textile wastewater by investigating its adsorption rates and isotherms using $\mathrm{NaIO}_{4}-\mathrm{NC}$ prepared from Eichhornia crassipes (water hyacinth).

\section{Materials and Methods}

2.1. Materials and Chemicals. The stem of water hyacinth (Eichhornia crassipes) weed for nanocellulose preparation was collected from southern region "Arba Minch," Lake abaya ("Ganta Garo" in the local name), Gamo Zone, Ethiopia. Textile industrial wastewater was collected from Hawassa city, southern region, Hawassa, Ethiopia. All the chemicals and reagents used throughout the experiments were in analytical grade. These include toluene (99\%, Loba Chemie Pvt. Ltd., India), ethanol (97\%, Tradewell International Pvt. Ltd., India), sodium hydroxide (99\%, Shraddha Associates (GUJ) Pvt. Ltd., India), conc. hydrochloric acid (35\%, Loba Chemie Pvt. Ltd., India), conc. sulfuric acid (69\%, Loba Chemie Pvt. Ltd., India), conc. nitric acid (69\%, Loba Chemie Pvt. Ltd., India), sodium chlorite (80\%, Shanghai ZZ New Material Tech. Co., Ltd., China), methylene blue trihydrate $(\mathrm{MB})\left(\mathrm{C}_{16} \mathrm{H}_{18} \mathrm{ClN}_{3} \mathrm{~S} \cdot 3 \mathrm{H}_{2} \mathrm{O}\right.$, Consolidated Chemical and Solvents LLC, USA), and sodium bicarbonate (99\%, Shraddha Associates (GUJ) Pvt. Ltd., India).

\subsection{Adsorbate}

2.2.1. Preparation of Synthetic Methylene Blue Stock Solution. A suitable quantity of $\mathrm{MB}$ was added to deionized water to prepare a stoke solution of $1000 \mathrm{mg} \cdot \mathrm{L}^{-1}$ in a $1000 \mathrm{~mL}$ volumetric flask. The standard series solutions were prepared from the previously prepared stock solution by using the dilution method. UV-VIS spectrometer (SM-spectrophotometer UV-Vis 1600, MaaLab Scientific Equipment Pvt. Ltd., India) was used to measure the concentrations of $\mathrm{MB}$ dyes. The standardization curve was obtained using the maximum absorbance at $\lambda \max 664 \mathrm{~nm}$ using MB standard series in the range of 10.0 and $40 \mathrm{mg} \cdot \mathrm{L}^{-1}$. The $\mathrm{pH}$ values of the prepared $\mathrm{MB}$ dye solution were measured by using a $\mathrm{pH}$ meter of $\mathrm{pH} 21$ Hanna instrument.

\subsubsection{Collection and Analysis of Real Textile Wastewater.} The textile industrial WW was collected from the run of the textile industrial zone of Hawassa city, southern region, Hawassa, Ethiopia. During the sample collection period, the textile industry was using $\mathrm{MB}$ as a dyeing agent. The $\mathrm{NaIO}_{4}{ }^{-}$ NC adsorbents prepared from Eichhornia crassipes were used for the WW treatment. Then, the measurement of physicochemical parameters of real textile $\mathrm{WW}$, including $\mathrm{NO}_{3}{ }^{-}, \mathrm{PO}_{4}{ }^{3-}, \mathrm{SO}_{4}{ }^{2-}, \mathrm{Cl}^{-}$, and chemical oxygen demand (COD), was performed using the titration method and UVVis measurement sequentially. The detailed experimental procedures were described by Zazou et al. [30]. The 
measurement BOD value was performed in agreement with the standard methods with the help of the Lovibond incubator [31].

\subsection{Adsorbent Preparation}

2.3.1. Preparation of Modified Nanocellulose $\left(\mathrm{NaIO}_{4}-\mathrm{NC}\right)$ from Water Hyacinth (Eichhornia crassipes). The stems of the collected water hyacinth (Eichhornia crassipes) weed samples were carefully cut into the length of $8 \mathrm{~mm}$, washed with distilled water repeatedly to remove dust particles, dried with the help of sun for 4 days, and ground using a grinder [32-36]. Short fibers of the sample were treated with $100 \mathrm{~mL}$ of $2 \mathrm{M} \mathrm{NaOH}$ solution at $50^{\circ} \mathrm{C}$ for 2 hours to remove the lignin and hemicelluloses present in lignocellulosic biomass. The sample treated with $\mathrm{NaOH}$ was washed well with deionized water repeatedly until it becomes neutral. The neutral mixture was filtered, centrifuged, and dried in the oven at $50^{\circ} \mathrm{C}$ for 8 hours. Then, it was ground into a pulp form and bleached with mixture of sodium chlorite $\left(\mathrm{NaClO}_{2}\right)$ and glacial acetic acid (in a ratio of $\left.2: 0.5\right)$ under mechanical stirring for 3 hours at the temperature of $80^{\circ} \mathrm{C}$. This procedure was repeated with one-third of the initial amount of bleaching mixture. Then, this mixture was centrifuged, washed, and filtered to form cellulose suspension. The suspension was hydrolyzed by $100 \mathrm{~mL}$ of $3 \mathrm{M}$ $\mathrm{H}_{2} \mathrm{SO}_{4}$ for 10 hours to break up the cell wall and to form a white cellulose nanomaterial suspension. Then, the cellulose nanomaterial suspension was dissolved in $0.2 \mathrm{~g} \cdot \mathrm{mL}^{-1}$ of $\mathrm{NaIO}_{4}$ in a $250 \mathrm{~mL}$ flask by covering it with aluminum foil and agitated at $50^{\circ} \mathrm{C}$ in the darkroom for 4 hours [32]. By the addition of $1 \mathrm{~g}$ ethylene glycol, the excess oxidizing agents were consumed, followed by the completion of the reaction. This procedure provides dialdehyde nanocellulose (DANC) through centrifugation at $1600 \mathrm{rpm}$ for $40 \mathrm{~min}$ and purified by successive water addition and centrifugation. This was sonicated in the presence of ionic liquid using a $16 \mathrm{kHz}$ (Branson digital Sonifier S-450D, South Korea), washed, filtered, and dried in a dark place to form $\mathrm{NaIO}_{4}-\mathrm{NC}$. Finally, $\mathrm{NaIO}_{4}-\mathrm{NC}$ was kept in a suitable place for characterization purposes. The flowchart for the preparation of $\mathrm{NaIO}_{4}-\mathrm{NC}$ is given in Figure 1.

Also, the reaction of $\mathrm{NC}$ with $\mathrm{NaIO}_{4}$ is given in Figure 2 .

2.4. Characterization. The X-ray diffraction (XRD) (XRD7000 X-ray diffractometer, Shimadzu Co., Japan) with $\mathrm{Cu}-$ $\mathrm{K} \alpha$ radiation $(\lambda=0.154 \mathrm{~nm})$ at $40 \mathrm{kV}$ and $40 \mathrm{~mA}$ under a $2 \theta$ diffraction angle from $10^{\circ}$ to $80^{\circ}$ at a scan rate of $2^{\circ} / \mathrm{min}$ characterization technique was used to determine the crystallinity size of the $\mathrm{NaIO}_{4}-\mathrm{NC}$ adsorbent material. Fourier transform infrared (FTIR) (Perkin Elmer65, PerkinElmer, Inc., Waltham, USA) spectrophotometer is an interesting method to determine the functional group of $\mathrm{NaIO}_{4}-\mathrm{NC}$ adsorbents. Its spectrum was recorded in the transmittance mode in the range of $4000-400 \mathrm{~cm}^{-1}$. The surface morphology of the different treatment phases of the $\mathrm{NaIO}_{4}-\mathrm{NC}$ adsorbent material was examined using field emission scanning electron microscopy (FE-SEM) (JCM- 6000plus, JEOL/EO, America) with energy-dispersive X-ray (EDX). The specific surface area measurement was determined by Brunauer-Emmett-Teller (BET) analysis.

2.5. Adsorption Experiments. To evaluate the methylene blue (MB) adsorption efficiency of the adsorbent, different experimental parameters such as solution $\mathrm{pH}$, adsorbent dose, $\mathrm{MB}$ initial concentration, and contact time optimization were performed. To perform this study, contact times ranged from 10 to $90 \mathrm{~min}$., $\mathrm{MB}$ initial concentration ranged from 10 to $40 \mathrm{mg} \cdot \mathrm{L}^{-1}$, adsorbent dose ranged from 0.4 to $2 \mathrm{~g}$, and solution $\mathrm{pH}$ ranged from 3 to 10 by making other parameters at fixed manner. Each of these parameters was performed in each of the $100 \mathrm{~mL}$ flasks at room temperature. For $\mathrm{pH}$ measurement, initially, the $\mathrm{pH}$ value of each solution was adjusted by the addition of $0.1 \mathrm{M} \mathrm{HCl}$ or $0.1 \mathrm{M} \mathrm{NaOH}$ solution and the $\mathrm{pH}$ change was measured using a $\mathrm{pH}$ meter ( $\mathrm{pH} 21$ Hanna instrument). After this, to prevent any side reaction, each flask was covered with aluminum foil in all experiments, and after the reaction completion, it was carefully filtered with filtrate paper No 42. Next to this procedure, the measurement of this solution was performed by UV-VIS spectrometer (SM-spectrophotometer UV-VIS 1600, MaaLab Scientific Equipment Pvt. Ltd., India) at a $\lambda_{\max }$ of $(664 \mathrm{~nm})$.

2.5.1. Adsorption Isotherms and Thermodynamics. The percentage removal $(\% R)$ of $\mathrm{MB}$ dye and amount of $\mathrm{MB}$ dye adsorbed on adsorbents at equilibrium were calculated by the following equation:

$$
\% R=\frac{C_{i}-C_{t}}{C_{i}} \times 100 .
$$

For the pollutant uptake mechanisms, the determination of uptake isotherm data for different materials is crucial. Three different models, namely, Langmuir, Freundlich, and Temkin isotherm models, were tested to investigate the removal of $\mathrm{MB}$ by using $\mathrm{NaIO}_{4}-\mathrm{NC}$ adsorbent. The equilibrium quantity and quantity at any specified time of $\mathrm{MB}$ dye adsorbed on $\mathrm{NaIO}_{4}-\mathrm{NC}$ adsorbent surface was calculated using the following equations, respectively:

$$
\begin{aligned}
& q_{e}=\frac{C_{i} \mathrm{MB}-C_{e} \mathrm{MB}}{S}, \\
& q_{t}=\frac{C_{i} \mathrm{MB}-C_{t} \mathrm{MB}}{S},
\end{aligned}
$$

where $C_{i}$ and $C_{t}$ are the initial and the final MB dye concentrations $\left(\mathrm{mg} \cdot \mathrm{L}^{-1}\right) ; q_{e}$ and $q_{t}$ represent the amount of $\mathrm{MB}$ dye concentrations adsorbed on $\mathrm{NaIO}_{4}$ - $\mathrm{NC}$ adsorbent surfaces at equilibrium and any specified time $\left(\mathrm{mg} \cdot \mathrm{g}^{-1}\right)$, respectively; $S$ represents the slurry dosage defined as the ratio between the mass of $\mathrm{NaIO}_{4}-\mathrm{NC}(\mathrm{g})$ to the initial volume of WW sample (L). Then, the thermodynamic study of the adsorption procedure was premeditated by considering the fundamental thermodynamic parameters, including change in Gibbs free energy $(\Delta G)$, change in enthalpy $(\Delta H)$, and 


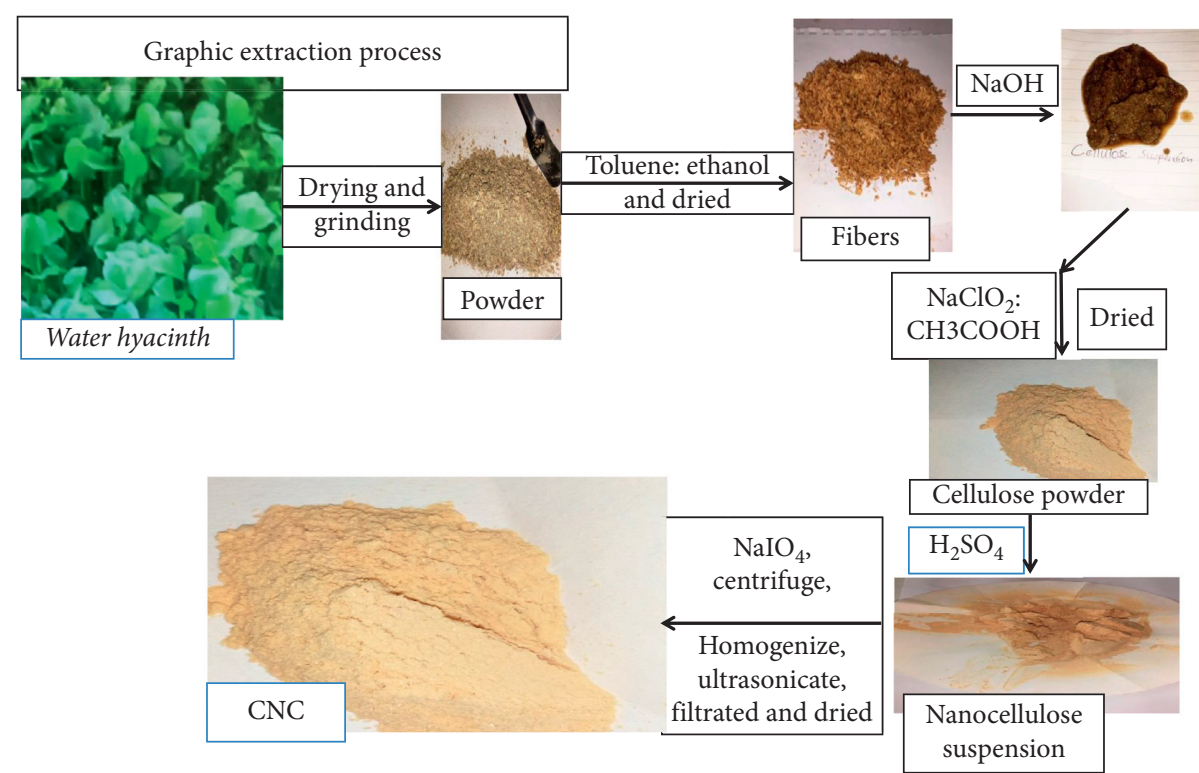

Figure 1: The flow hart representation of $\mathrm{NaIO}_{4}-\mathrm{NC}$ preparation from the stems of Eichhornia crassipes.

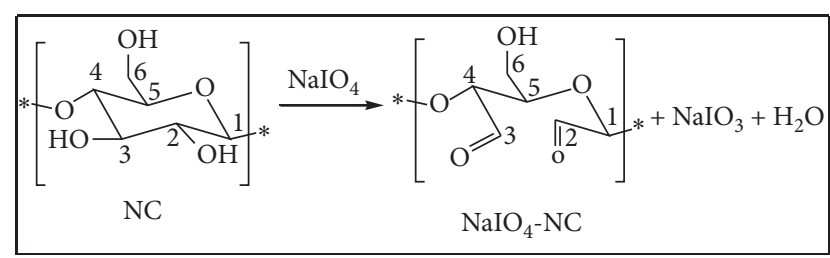

FIGURE 2: The oxidation reaction mechanism of $\mathrm{NC}$ with $\mathrm{NaIO}_{4}$.

change in entropy $(\Delta S)$ values. Thus, the thermal behavior of the adsorption process was carried out by making all the predetermined values of parameters (solution $\mathrm{pH}$, sorbent dosage, contact time, agitation speed, and $\mathrm{Pb}(\mathrm{II})$ ions initial concentration) at optimum value and the temperature was varied from 25 to $40^{\circ} \mathrm{C}[37,38]$.

2.5.2. Adsorption Kinetics. The rate of color removal mechanisms was conducted through the experimental measurement of contact time ranging from 15 to $150 \mathrm{~min}$ through keeping all parameters (solution $\mathrm{pH}$, adsorbent dose, and MB dye initial concentration) at optimized value.

2.6. Desorption and Adsorbent Regeneration Study. Firstly, $\mathrm{NaIO}_{4}-\mathrm{NC}$ adsorbent was saturated with $30 \mathrm{mg} \cdot \mathrm{L}^{-1}$ of $\mathrm{MB}$ dye solution. Then, $1 \mathrm{~g} \mathrm{NaIO}_{4}-\mathrm{NC}$ adsorbent dosage was added to the mixture and the mixture was shaken for $60 \mathrm{~min}$. After this, $\mathrm{NaIO}_{4}-\mathrm{NC}$ adsorbent was separated from the mixture and washed with deionized water. Then, desorption studies were performed by shaking $\mathrm{NaIO}_{4}-\mathrm{NC}$ adsorbent containing the adsorbate (MB) with $1 \mathrm{M}$ of $\mathrm{HCl}$ treatment for $60 \mathrm{~min}$. The reobtained $\mathrm{NaIO}_{4}-\mathrm{NC}$ adsorbent was carefully conducted for the cationic $\mathrm{MB}$ dye removal by replicating the laboratory experiments for at least 13 successive cycles using the same adsorbent.

\section{Results and Discussion}

3.1. Characterization. The $\mathrm{NaIO}_{4}-\mathrm{NC}$ sorbent was characterized with the help of FTIR, XRD, and FE-SEM with EDX modern instruments. Directly, the information of functional groups of $\mathrm{NaIO}_{4}-\mathrm{NC}$ adsorbent before and after adsorption was observed by FTIR spectroscopy. FTIR spectra of $\mathrm{NaIO}_{4}{ }^{-}$ $\mathrm{NC}$ obtained by acid hydrolysis before and after adsorption are shown in Figure 3(a). The spectral bands at $3406 \mathrm{~cm}^{-1}$ before and after adsorption indicated the presence of $\mathrm{O}-\mathrm{H}$ stretching vibrations of cellulose I; those at $2853-2925 \mathrm{~cm}^{-1}$ before and after adsorption indicated the presence of $\mathrm{C}-\mathrm{H}$ stretching; those at $1730 \mathrm{~cm}^{-1}$ before and after adsorption indicated the presence of $\mathrm{C}-\mathrm{O}$ stretching vibration of aldehyde groups due to the addition of $\mathrm{NaIO}_{4}$ to $\mathrm{NC}$; those at $1058 \mathrm{~cm}^{-1}$ and $1040 \mathrm{~cm}^{-1}$ before and after adsorption, respectively, indicated C-O-C stretching of cellulose I [39]. The broadband and the sharp band before and after adsorption, respectively, at $671 \mathrm{~cm}^{-1}$ in the spectra correspond to $\beta$-glycosidic links between the glucose units of cellulose. The presence of this band in the NC spectra is interesting since it is an indication that cellulosic material may have not been lost during the acid hydrolysis. The additional band appears at $599.9 \mathrm{~cm}^{-1}$ maybe due to the interaction between adsorbent/adsorbate confirming the adsorption of cationic $\mathrm{MB}$ dye on negatively charged $\mathrm{NaIO}_{4}-\mathrm{NC}$ adsorbent surface [12] and it also indicates that the roles of alkyl halides functional groups such as $\mathrm{C}-\mathrm{I}$ in the adsorption process of $\mathrm{MB}$ onto the adsorbents were significant. Generally, $\mathrm{NaIO}_{4}$ NC adsorbent has plenty of hydroxyl, carbonyl, carboxyl, and ester functional groups, which are most reactive to adsorb MB dye cations through electrostatic interaction formed between the negatively charged $\mathrm{NaIO}_{4}-\mathrm{NC}$ adsorbent and positively charged MB dye.

The $\mathrm{NaIO}_{4}$-NC sorbent crystalline size was determined using the XRD diffractogram (Figure 3(b)). The XRD spectra exhibited a peak at $2 \theta=16.6^{\circ}, 22.6^{\circ}$, and $34.5^{\circ}$, which are 


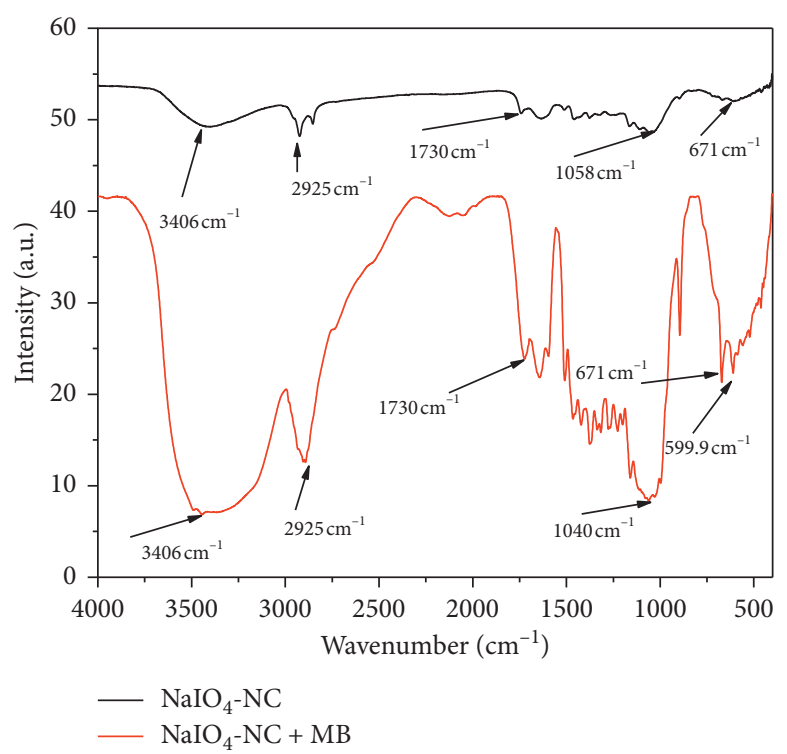

(a)

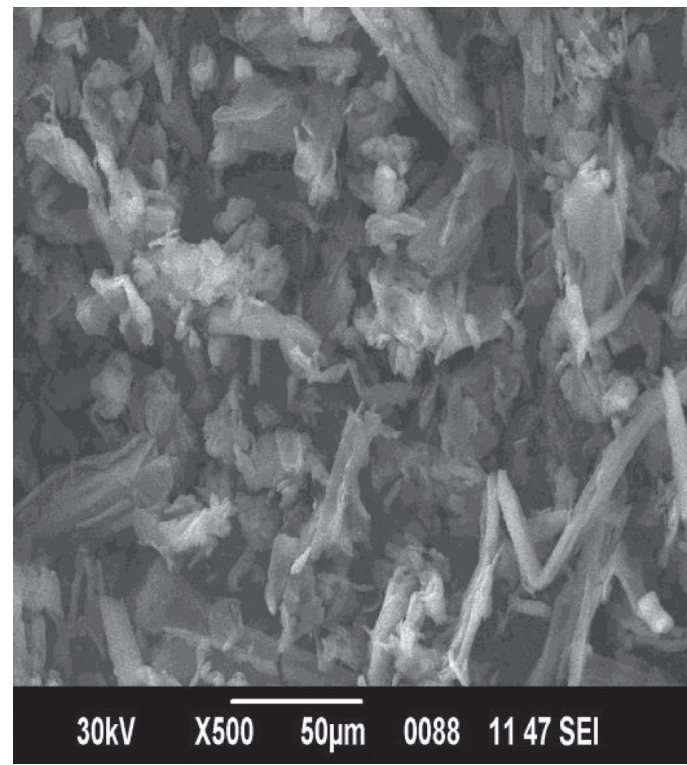

(c)

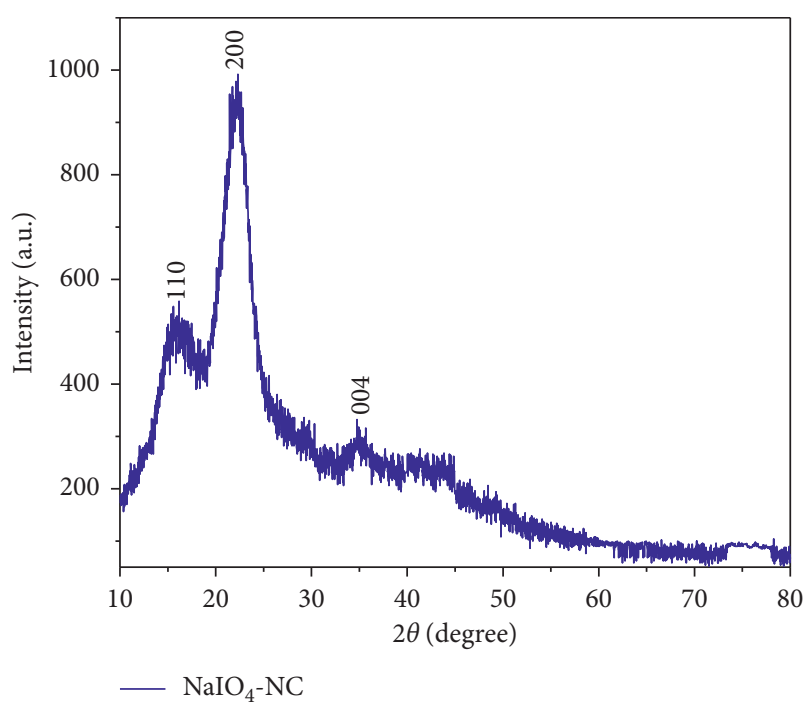

(b)

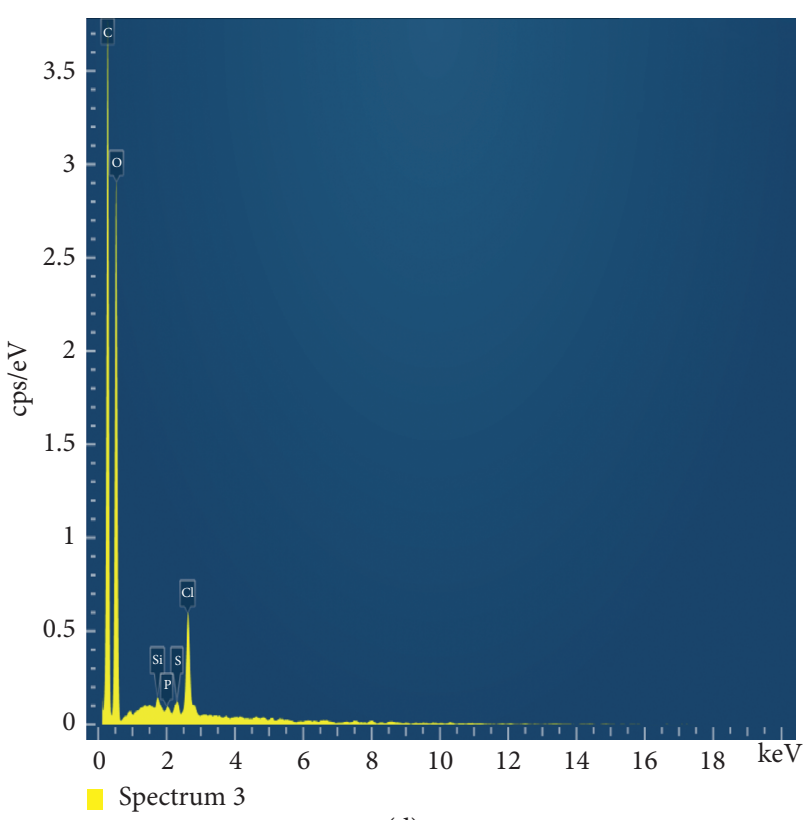

(d)

FIgURE 3: (a) XRD pattern; (b) FTIR spectrum; (c) SEM images; (d) EDX of $\mathrm{NaIO}_{4}$-NC sorbent.

supposed to represent the typical cellulose I structure and assigned to 110,200 , and 004 planes, respectively [40, 41]. The spectra have exhibited the amorphous and semicrystalline nature of the adsorbents with a reduced degree of crystallinity. This is because the crystalline region was oxidized progressively with the reaction of $\mathrm{NaIO}_{4}$ with nanocellulose suspension.

Figure 3(c) shows the FE-SEM micrographs of the prepared $\mathrm{NaIO}_{4}-\mathrm{NC}$ sorbent. The FE-SEM images show that $\mathrm{NaIO}_{4}-\mathrm{NC}$ sorbent was a cylindrical rod-like shape, with a slightly rough surface, associated with heterogeneous pore distribution through its matrix. Their energy-dispersive $\mathrm{X}$-ray diffraction (EDX) attached with FE-SEM was used for elemental analysis of $\mathrm{NaIO}_{4}$-NC. The EDX spectrum shown in Figure 3(d) exhibited the peaks for carbon, oxygen, chlorine, and sulfur corresponding to their atomic weights, respectively. The $\mathrm{NaIO}_{4}$-NC adsorbent contains 0.84 wt $\%$ and 0.09 wt $\%$ elemental impurity of chlorine and sulfur along with the main components, such as carbon $(52.68 \%)$ and oxygen (44.65), as shown in Figure 3(d). This elemental impurity is due to the acid hydrolysis of cellulose suspension.

Brunauer-Emmett-Teller (BET) data analysis is performed according to the BET adsorption isotherm linear equation (4) to determine the specific surface area of $\mathrm{NaIO}_{4}$ NC. Its measurement was carried out using $\mathrm{N}_{2}$ gas as an adsorbate at a temperature of $77 \mathrm{~K}$. 


$$
\frac{P / P_{o}}{n\left(1-P / P_{o}\right)}=\frac{C-1}{\left(X_{m} C\right)}\left(\frac{P}{P_{o}}\right)+\frac{1}{X_{m} C},
$$

where $P_{o}$ and $P$ are saturated and partial vapor pressure of $\mathrm{N}_{2}$ gas at equilibrium in pa, respectively; $n$ is the volume of $\mathrm{N}_{2}$ gas adsorbed at STP in $\mathrm{mL} ; X_{m}$ is BET monolayer capacity; $C$ is a dimensionless constant associated with the enthalpy of $\mathrm{N}_{2}$ gas adsorption on the adsorbent.

For the well-defined BET monolayer capacity of the nanoparticle materials, the value of $C$ should be $\geq 80$ [42]. Thus, the results indicated that the $\mathrm{C}$ value of $\mathrm{NaIO}_{4}-\mathrm{NC}$ is 192.8 , which is $\geq 80$. Figure 4 (a) presents the linear plots of $\left[\left(P / P_{o}\right) /\left(n\left(1-P / P_{o}\right)\right)\right]$ versus $P / P_{o}$, providing a straight line with the approximate relative pressure ranging from 0.05 to 0.3 . The linear regression value $\left(R^{2}\right)$ obtained from this plot was 0.9985 , which is greater than 0.995 . This result confirms the acceptability level of $R^{2}$ value. The specific surface area (SSA) in $\mathrm{m}^{2} \cdot \mathrm{g}^{-1}$ is calculated according to the following equation:

$$
a_{s}=\frac{X_{m} L \sigma_{m}}{m \times 22400},
$$

where $a_{s}$ is the BET SSA of the $\mathrm{NaIO}_{4}$ - NC of mass $m$ in grams, $L$ is Avogadro's constant $\left(6.022 \times 10^{23} \mathrm{~mol}^{-1}\right), \sigma_{m}$ is molecular adsorptive cross-sectional area occupied by $\mathrm{N}_{2}$ gas molecule in the complete monolayer (equal to $0.162 \mathrm{~nm}^{2}$ for $\mathrm{N}_{2}$ gas), and the 22400 is the volume occupied by 1 mole of $\mathrm{N}_{2}$ gas at STP, in $\mathrm{mL}$.

The BET plot of $\mathrm{NaIO}_{4}-\mathrm{NC}$ in Figure 4(b) has indicated the cylindrical shape model. The symbols used were those given in the 2007 edition of the IUPAC manual [43]. Results indicated that the as-prepared $\mathrm{NaIO}_{4}-\mathrm{NC}$ adsorbent has a higher SSA of $123.9 \mathrm{~m}^{2} \cdot \mathrm{g}^{-1}$. Therefore, $\mathrm{NaIO}_{4}-\mathrm{NC}$ has shown higher MB adsorption efficiency due to the decrease of the particle size, the increase of SSA, and the increase of surface roughness.

\subsection{Treatment of the Real Textile Wastewater (WW) Relative} to Synthetic Wastewater $(W W)$. To assess the effectiveness of the treatment process by the adsorbent, it is possible to investigate the uptake of real textile industrial WW, containing $\mathrm{MB}$ as the main dye, relative to synthetic WW. The textile industry $\mathrm{WW}$ was characterized by determining its $\mathrm{pH}, \mathrm{EC}, \mathrm{COD}, \mathrm{BOD}, \mathrm{NO}_{3}{ }^{-}, \mathrm{PO}_{4}{ }^{3-}, \mathrm{SO}_{4}{ }^{2-}$, and $\mathrm{Cl}^{-}$before and after adsorption, given in Table 1 . The uptake investigations were performed by using $30 \mathrm{~mL}$ of $\mathrm{WW}$ with 0.08 , $0.5,1,1.5$, and $2 \mathrm{~g}$ of $\mathrm{NaIO}_{4}$ - $\mathrm{NC}$ adsorbent dose for $60 \mathrm{~min}$. of reaction time at $25^{\circ} \mathrm{C}$. From this optimization process, the optimum value of the adsorbent dose obtained was $1 \mathrm{~g}$ because the maximum uptake value was detected at this value of the adsorbent dose. Figure 5 shows that the absorbance spectra of synthetic WW (a) and real WW (b), respectively, before and after treatment, and the comparison study for the uptake capacity of $\mathrm{MB}$ from synthetic wastewater and real textile industrial WW solutions (c). From the UV-Vis spectra, it is possible to conclude that percentage of removal $(\% R)$ of synthetic $\mathrm{MB}$ was higher than that of the real WW. This may be because the real WW treatment was hindered by the presence of a different matrix that competes with the MB dye. The decreased values for the physicochemical property measurement of textile industrial WW were observed after treatment, as shown in Table 1. Here, the concentration values of $\mathrm{COD}, \mathrm{Cl}^{-}, \mathrm{Mg}^{2+}$, and $\mathrm{Cu}^{2+}$ decreased by approximately $95 \%, 100 \%, 93 \%$, and $95 \%$, respectively. Furthermore, the comparison study was conducted and presented in Figure 5(c). The findings have been shown that a very high $\% R(99.99 \%)$ of cationic $\mathrm{MB}$ was removed from synthetic WW and relatively less $\% R(78.5 \%)$ of cationic $\mathrm{MB}$ was removed from real WW by using $1 \mathrm{~g}$ $\mathrm{NaIO}_{4}-\mathrm{NC}$ adsorbent and $30 \mathrm{mg} / \mathrm{L}$ initial concentration and $60 \mathrm{~min}$. contact time. These great variations of adsorption efficiency were observed between the two systems were because in real $\mathrm{WW}$, there are competing pollutants that reduce the adsorption efficiency of $\mathrm{MB}$ in real WW by occupying the surfaces of the adsorbent.

\subsection{Adsorption Studies}

3.3.1. Effects of Initial MB Concentration. Figure 6(a) indicates the effects of initial $\mathrm{MB}$ solution concentrations $(10-40 \mathrm{mg} / \mathrm{L})$ for the removal of cationic $\mathrm{MB}$ using $\mathrm{NaIO}_{4}{ }^{-}$ NC adsorbent. Findings indicated that on varying the pollutant $\mathrm{MB}$ concentration from 10 to $40 \mathrm{mg} / \mathrm{L}$, the $\% R$ is increased from 39.25 to $78.21 \%$ using $\mathrm{NaIO}_{4}$ - $\mathrm{NC}$ adsorbent. These results are in agreement with findings reported by Munir et al. and Gupta et al. [44, 45] on MB dye removal. The adsorption process can be both very rapid and slow. At low initial concentration, the dye removal process was very fast until the optimum initial concentration due to the presence of more available reactive sites on the surface of the $\mathrm{NaIO}_{4}-\mathrm{NC}$ adsorbent because of the surface modification of NC by using sodium periodate. At optimum initial concentration of $30 \mathrm{mg} / \mathrm{L}$, the maximum adsorption efficiency and percent removal were observed. At this point, the adsorbent evidently displayed maximum dye percent removal $(\% R)$ capacity of $78.1 \%$. Conversely, beyond this point, the \% $R$ becomes constant. This adsorption process may be attributed to the penetration diffusion of $\mathrm{MB}$ into the inner surface of the $\mathrm{NaIO}_{4}$ - $\mathrm{NC}$ adsorbent [46].

3.3.2. Effect of Contact Time. The time necessary for achieving equilibrium is one of the greatest significant aspects, which decide the effectiveness of the progression, possibility, and the wastewater treatment cost [47]. The effect of contact time on the $\mathrm{MB}$ dye removal was conducted by varying the contact time ranging from 10 to $90 \mathrm{~min}$. at optimum $\mathrm{NaIO}_{4}$ - $\mathrm{NC}$ dose of $1 \mathrm{~g}$, temperature $(T)$ of $25^{\circ} \mathrm{C}$, and initial concentration of MB of $30 \mathrm{mg} \cdot \mathrm{L}^{-1}$ (Figure 6(b)). These optimum values have shown the values at which the higher adsorption efficiency was detected. As seen from Figure 6(b), the color removal is increased with increasing the time up to the optimum contact time of $60 \mathrm{~min}$, due to the presence of highly reactive sites resulted from the increased number of carbonyl functional groups on the surfaces of the adsorbent [48]. The maximum percentage of color removal $(\% R)$ of $78.1 \%$ and high adsorption efficiency 


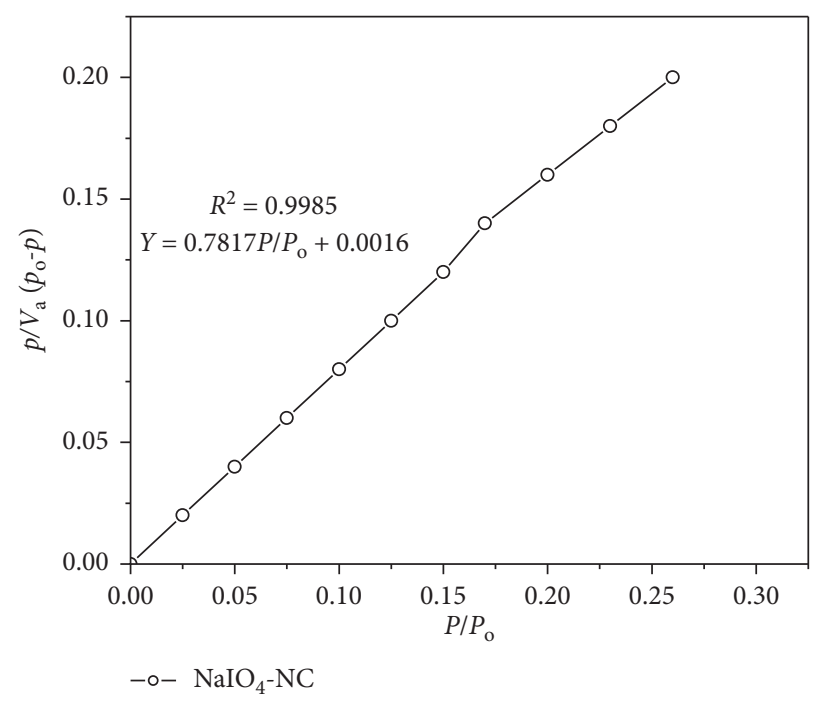

(a)

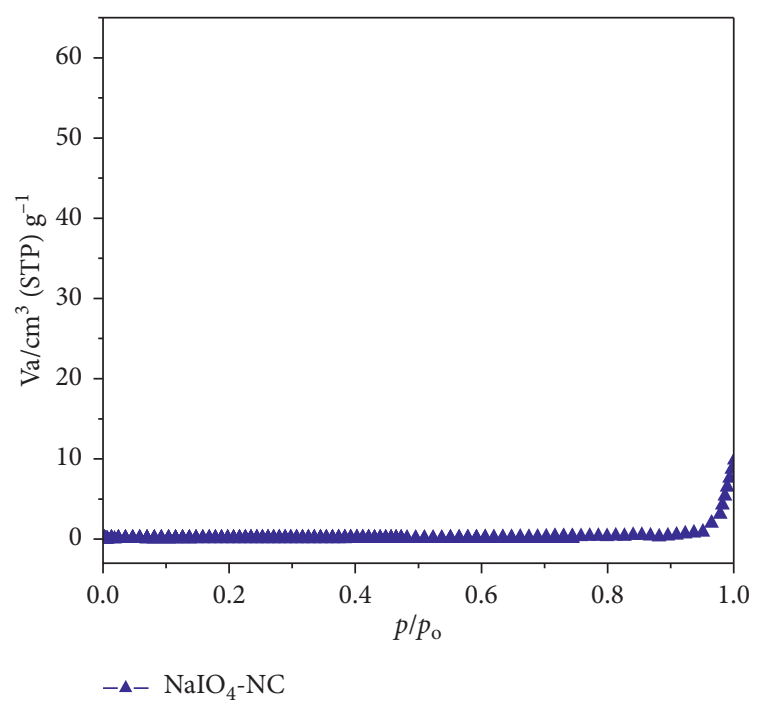

(b)

Figure 4: (a) The linear plot of $\mathrm{NaIO}_{4}$-NC; (b) the BET plot of $\mathrm{NaIO}_{4}$ - $\mathrm{NC}$ adsorbent.

TABLE 1: Physicochemical properties of the WW used in the study before and after treatment.

\begin{tabular}{lcc}
\hline Parameter & Before treatment & After treatment \\
\hline $\mathrm{pH}$ & $7.4 \pm 0.03$ & $7.05 \pm 0.03$ \\
$\mathrm{Color}$ & Black & Colorless \\
$\mathrm{EC}\left(\mu \mathrm{S} \cdot \mathrm{cm}^{-1}\right)$ & $5.08 \pm 0.5$ & $5.02 \pm 0.5$ \\
$\mathrm{COD}(\mathrm{mg} / \mathrm{L})$ & $504 \pm 0.2$ & $28.9 \pm 0.2$ \\
$\mathrm{BOD}(\mathrm{mg} / \mathrm{L})$ & $92 \pm 0.04$ & $60.5 \pm 0.04$ \\
$\mathrm{NO}_{3}{ }^{-}(\mathrm{mg} \cdot \mathrm{N} / \mathrm{L})$ & $40.8 \pm 0.04$ & $0.08 \pm 0.04$ \\
$\mathrm{PO}_{4}{ }^{3-}(\mathrm{mg} \cdot \mathrm{P} / \mathrm{L})$ & $0.4 \pm 0.02$ & $0.05 \pm 0.02$ \\
$\mathrm{SO}_{4}{ }^{-}(\mathrm{mg} \cdot \mathrm{P} / \mathrm{L})$ & $100 \pm 0.3$ & $45 \pm 0.3$ \\
$\mathrm{Cl}^{-}(\mathrm{mg} / \mathrm{L})$ & $18.5 \pm 0.03$ & $0.2 \pm 0.03$ \\
$\mathrm{Mg}^{2+}(\mathrm{mg} / \mathrm{L})$ & $54.2 \pm 0.04$ & $4.2 \pm 0.04$ \\
$\mathrm{Cu}^{2+}(\mathrm{mg} / \mathrm{L})$ & $24.26 \pm 0.02$ & $1.2 \pm 0.02$ \\
\hline
\end{tabular}

BOD: biological oxygen demand; COD: chemical oxygen demand.

were observed at the optimum contact time of $60 \mathrm{~min}$. After this time, the $\% R$ processes proceed in a fixed manner. This is because the adsorbent has limited active sites and steric hindrance on its surface, which makes the adsorption process slow down and reach equilibrium. Therefore, determining the optimum contact time for the adsorption process is very significant because using more than the required contact time would result in higher energy stresses and would be economically costly [44].

3.3.3. Effect of Adsorbent Dose. Figure 7(a) indicates the effect of adsorbent dose on adsorption ability and degree of color removal at the optimum temperature of $25^{\circ} \mathrm{C}, \mathrm{MB}$ initial concentration of $30 \mathrm{mg} \cdot \mathrm{L}^{-1}$, the contact time of 60 min., and solution $\mathrm{pH}$ of 8 . Different doses of $\mathrm{NaIO}_{4}-\mathrm{NC}$ adsorbent ranged from 0.4 to $2 \mathrm{~g}$ were used in the experiments. Results exhibited that the increase of the adsorbent dosage from 0.4 to $1 \mathrm{~g}$ increases the $\% R$ from $35.51 \%$ to $78.50 \%$. The maximum adsorption efficiency was detected at the optimum adsorbent dose of $1 \mathrm{~g}$. After this optimum value, the color removal remains constant due to the quantity of ions bond to the adsorbent and the number of mobile ions in the wastewater becomes fixed even with an extra addition of the adsorbents dose [23]. Conversely, the increased $\% R$ and efficiency were reported by Tan et al. [23] for $\mathrm{MB}$ dye removal using cellulose-based nanomaterials as an adsorbent from synthetic wastewater. The relatively low efficiency and percent removal were observed in this study due to the computation of other contaminants to the surface of the adsorbent since this study was focused on the removal of cationic dye from real textile industrial wastewater. The cationic $\mathrm{MB}$ dye adsorption mechanism with its computing pollutants by $\mathrm{NaIO}_{4}-\mathrm{NC}$ is presented in Figure 8 .

3.3.4. Effect of Solution $p H$. The solution $\mathrm{pH}$ circumstance in which the surface charge density equals zero is termed the $\mathrm{pH}$ point of zero charges (pHPZC). Figure $7(\mathrm{~b})$ indicates the $\mathrm{pHPZC}$ of the material and its value was 6.5. From the plot, it is possible to deduce that the adsorbent surface is positively charged at $\mathrm{pH}<6.5$ and becomes negatively charged at $\mathrm{pH}>6.5$. Thus, the high uptake capacity was observed at $\mathrm{pH}>6.5$, which is a $\mathrm{pH}$ of 8 . For $\mathrm{pH}$ values of $\mathrm{pH}<6.5$ uptake process is delayed by the repulsive electrostatic force of attractions between the $\mathrm{MB}$ dye ions and positively charged functional groups of the $\mathrm{NaIO}_{4}-\mathrm{NC}$ adsorbent [49].

The effect of solution $\mathrm{pH}$ on $\mathrm{MB}$ cation removal was presented (Figure $7(\mathrm{c}))$. The adsorbent $\left(\mathrm{NaIO}_{4}-\mathrm{NC}\right)$ used in this study has shown that high color removal abilities in the solution $\mathrm{pH}$ range of $3-8$. These are a result of the presence of hydrogen ions $\left(\mathrm{H}^{+}\right)$on the adsorption site of $\mathrm{MB}$ cations to the surface of the adsorbent active sites. At low $\mathrm{pH}$ values, the interaction of $\mathrm{MB}$ cations with sorbents is decreased owing to the $\mathrm{H}^{+}$ions competing with the $\mathrm{MB}$ cations on the active sites of the adsorbent. Moreover, as the WW $\mathrm{pH}$ increases (i.e., less $\mathrm{H}^{+}$ions), $\mathrm{MB}$ cations adsorption onto the 


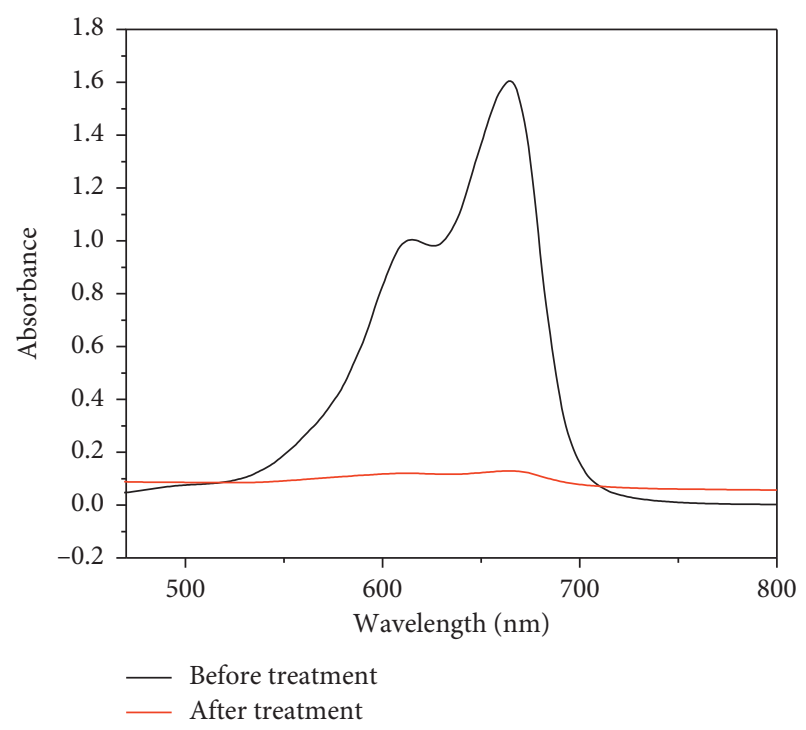

(a)

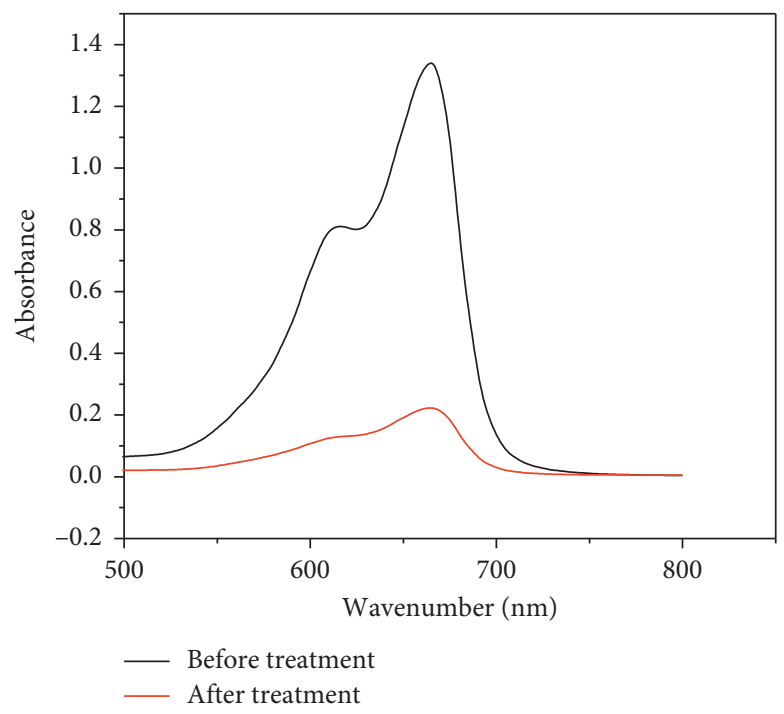

(b)

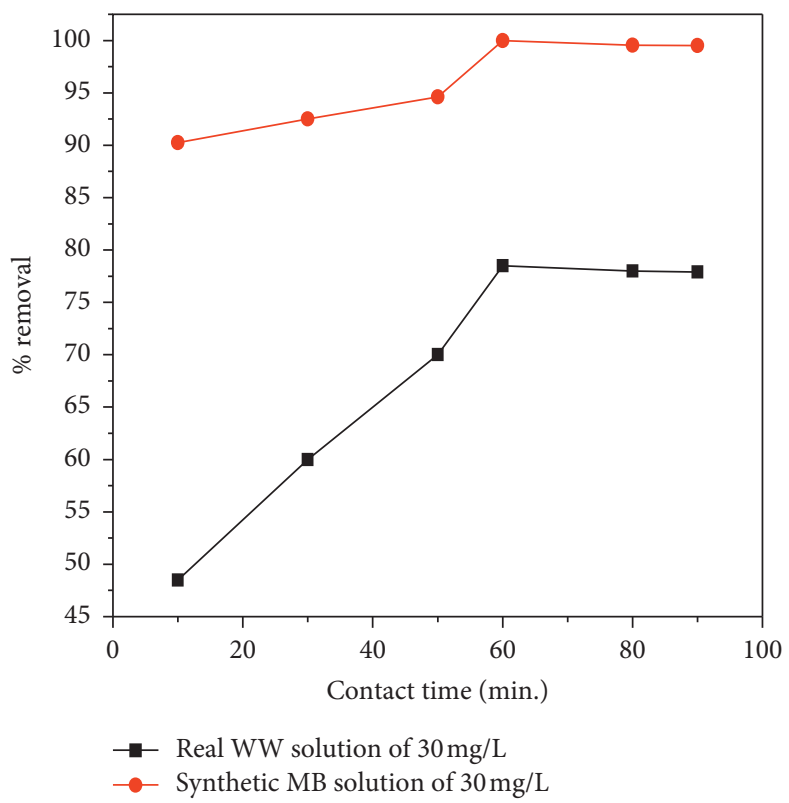

(c)

Figure 5: UV-Visible spectra of synthetic MB: (a) real textile wastewater; (b) before and after 60 min. of treatment at $\lambda_{\text {max }}$ of 664 . The comparison study for the uptake capacity of MB from synthetic wastewater and real textile industrial WW solutions (c).

$\mathrm{NaIO}_{4}-\mathrm{NC}$ adsorbent surfaces increases, leading to higher color removal towards the optimum $\mathrm{pH}$ value of 8 . At an alkaline $\mathrm{pH}$ value, the adsorbent becomes negatively charged and $\mathrm{MB}$ cations effectively adsorbed onto the surfaces of the adsorbent. This result was in agreement with the study reported by Salama et al. [50] on the removal of MB on oxidized cellulose-reinforced silica gel.

3.4. Adsorption Isotherms. Here, adsorption isotherm models describe the distribution of the cationic MB among the liquid and solid states according to expectations related to the heterogeneity or homogeneity of the $\mathrm{NaIO}_{4}-\mathrm{NC}$ adsorbent surface, the category of coverage, and the prospect of contact in the cationic MB. This study was performed by mixing $1 \mathrm{~g}$ of $\mathrm{NaIO}_{4}-\mathrm{NC}$ adsorbent in different concentrations of MB, $10,15,20,25,30,35$, and $40 \mathrm{mg} \cdot \mathrm{L}^{-1}$, at a $\mathrm{pH}$ of 8 for $60 \mathrm{~min}$. of contact time. Langmuir, Freundlich, and Temkin isotherms were tested to investigate the removal of $\mathrm{MB}$ by using $\mathrm{NaIO}_{4}-\mathrm{NC}$ adsorbent and their equation was presented in equations (6), (8), and (9), respectively. Langmuir isotherm model describes the information for the adsorption of $\mathrm{MB}$ dye onto the surface of $\mathrm{NaIO}_{4}-\mathrm{NC}$ adsorbent homogeneously and the dye molecule formed a monolayer onto the adsorption sites [51]. The Freundlich isotherm model predicts that multilayer adsorption occurs on the uneven surface of the $\mathrm{NaIO}_{4}-\mathrm{NC}$ adsorbent and the Temkin isotherm model is employed to designate the 


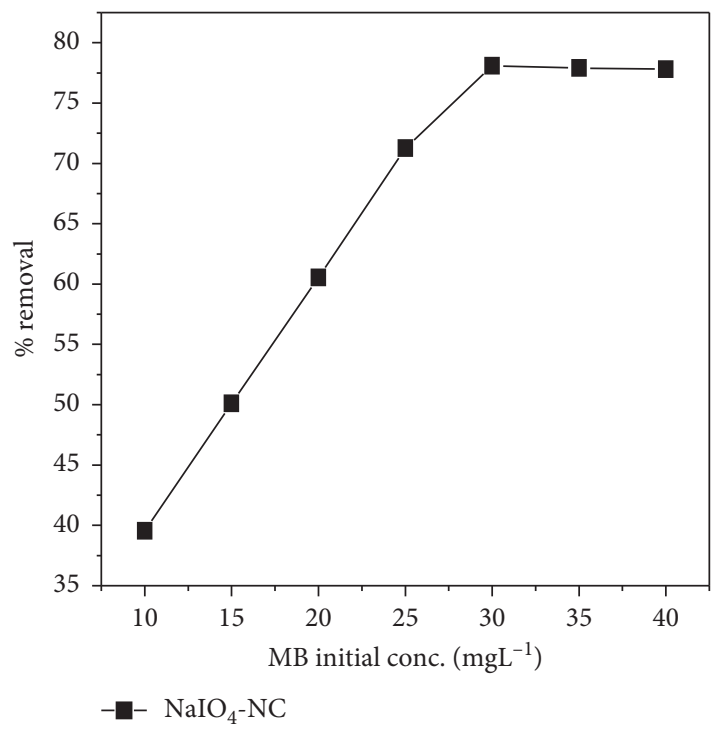

(a)

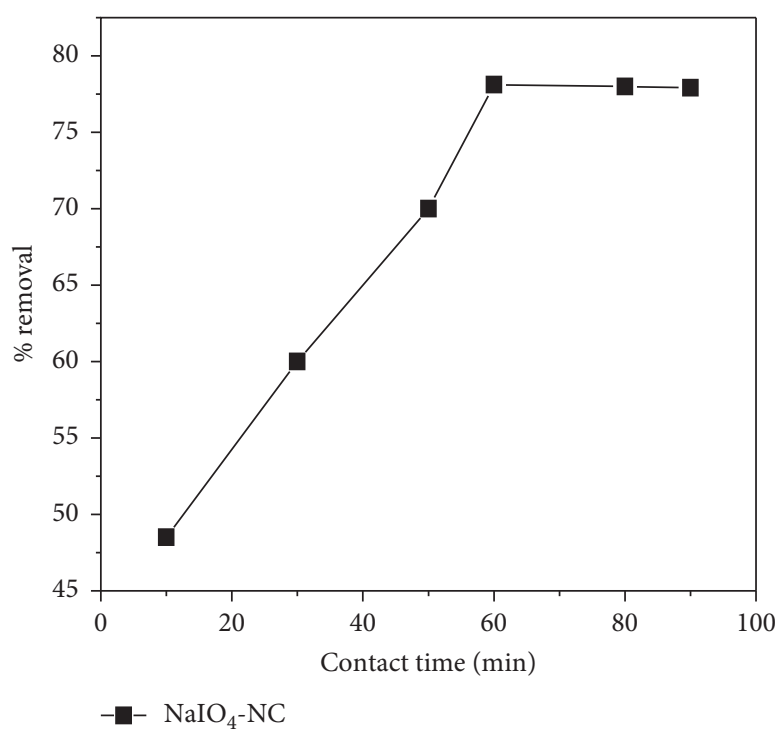

(b)

Figure 6: The effect of $\mathrm{MB}$ initial concentration (a) and contact time (b) on the color removal at optimum temperature of $25^{\circ} \mathrm{C}$, adsorbent dosage of $1 \mathrm{~g}$, and solution $\mathrm{pH}$ of 8 .

communication among $\mathrm{MB}$ and $\mathrm{NaIO}_{4}-\mathrm{NC}$ adsorbents such as ion exchange and electrostatic interaction where the molecules in the layer will decrease in linear with coverage than logarithmic [52].

Figures 9(a)-9(c) indicate that Langmuir and Freundlich isotherms are fitted for $\mathrm{MB}$ dye removal using $\mathrm{NaIO}_{4}-\mathrm{NC}$ adsorbent and Temkin isotherm is not suitable for the adsorption process due to the low $R^{2}$ value. Table 2 describes the $\mathrm{MB}$ dye uptake by the adsorbent well fitting to Langmuir isotherm compared to Freundlich and Temkin isotherms because the $R^{2}$ values were $0.965,0.959$, and 0.846 , respectively. The maximum MB removal ability $\left(q_{\max }\right)$ of the $\mathrm{NaIO}_{4}$-NC sorbent per unit mass was $90.91 \mathrm{mg} / \mathrm{g}$ from real textile industrial wastewater. This result indicated relatively low removal efficiency compared to the results reported by Salama et al. [44] regarding the removal of MB on oxidized cellulose-reinforced silica gel, which maybe is attributed to the presence of different matrix in real wastewater. If there is no computing matrix other than the target adsorbate; then, all the active sites of the adsorbent were occupied by the target element. This indicated that when an active site of adsorbent was occupied by a molecule, no other molecules could be adsorbed onto the surface [53]. This result was in agreement with the study reported by Qian et al. [54] for the adsorption of $\mathrm{MB}$ on modified bamboo hydrochar adsorbent. The calculated value for $b$ and a dimensionless equilibrium parameter (RL) of $\mathrm{NaIO}_{4}-\mathrm{NC}$ sorbent were $0.075 \mathrm{~L} \cdot \mathrm{mg}^{-1}$ and 0.308 , respectively. A dimensionless equilibrium parameter $(\mathrm{RL})$ value calculated using equation (7) for $\mathrm{MB}$ was found in the range of $0<R L<1$, representing the removal process by $\mathrm{NaIO}_{4}$ - $\mathrm{NC}$ adsorbent was favorable. Typically, the degree of favorability is linked to the irreversibility of the adsorption system, and this may afford the identification of the interactions between $\mathrm{NaIO}_{4}-\mathrm{NC}$ adsorbent and the MB dye adsorbate [55]. Also, the magnitude for $\mathrm{Kf}$ and $n$ of $\mathrm{NaIO}_{4}$ - $\mathrm{NC}$ sorbent for MB removal was 1.02 and 2.22, respectively, which was found between 1 and 10 . This has shown that the results indicated an easy MB removal from wastewater and clearly described the proposed removal mechanism. Therefore, $\mathrm{NaIO}_{4}-\mathrm{NC}$ adsorbent could be considered as one of the renewable, biodegradable, nontoxic, and highly efficient adsorbents for the removal of cationic $\mathrm{MB}$ dye with slow step bringing factors on the available surface of the adsorption places after reaching equilibrium position.

Table 2 presents the calculated Gibbs free energies values of cationic MB dye obtained by equation (10). The values of this thermodynamic parameter were determined at temperatures of $20-45^{\circ} \mathrm{C}$; the optimum temperature was found to be $25^{\circ} \mathrm{C}$. The more negative value of $\Delta G^{\circ}$ occurred at the operational temperature of $25^{\circ} \mathrm{C}$. This suggests that uptake abilities rise by descending the temperature and the negative value for $\Delta G^{\circ}$ confirms that the uptake mechanism of cationic MB dye was spontaneous and feasible [56-59].

$$
\begin{aligned}
\frac{C_{e}}{Q_{e}} & =\frac{1}{b Q_{\max }}+\frac{C_{e}}{Q_{\max }}, \\
R_{L} & =\frac{1}{1+b C_{0}}, \\
\log q_{e} & =\log k_{f}+\frac{1}{n} \log C_{e}, \\
Q_{e} & =\frac{R T}{B}+\log A C_{e}, \\
\Delta G^{\circ} & =-R T \ln k_{C},
\end{aligned}
$$

where $q_{\max }$ is the maximum removal capability of $\mathrm{MB}$ per unit mass of adsorbent $\left(\mathrm{mg} \cdot \mathrm{g}^{-1}\right), K_{f}$ is the adsorption 


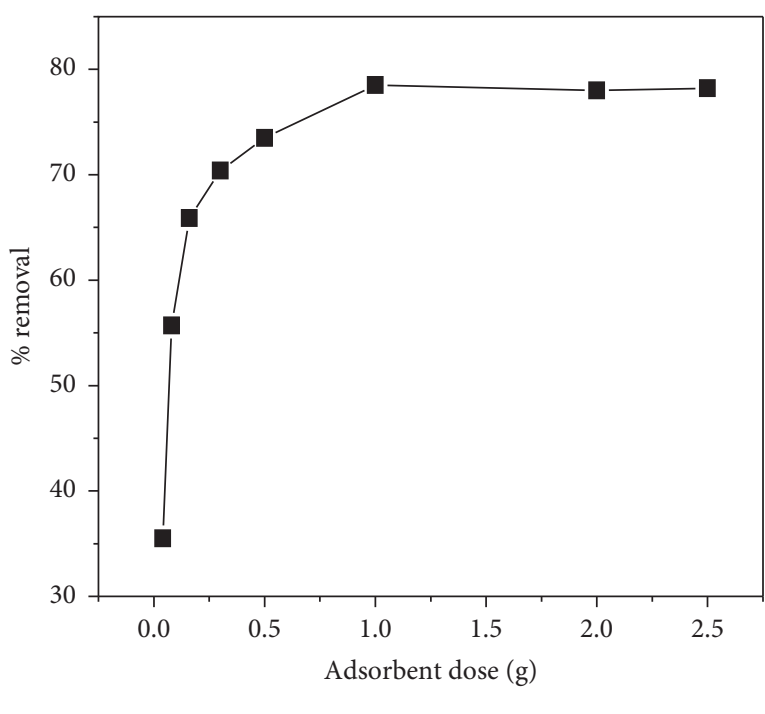

$\mathrm{NaIO}_{4}$ - $\mathrm{NC}$

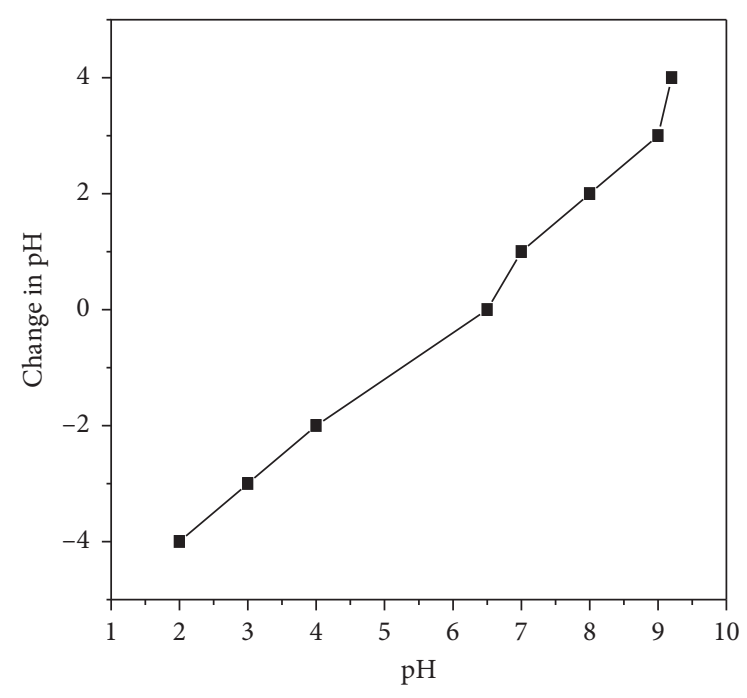

$\mathrm{NaIO}_{4}-\mathrm{NC}$

(a)

(b)

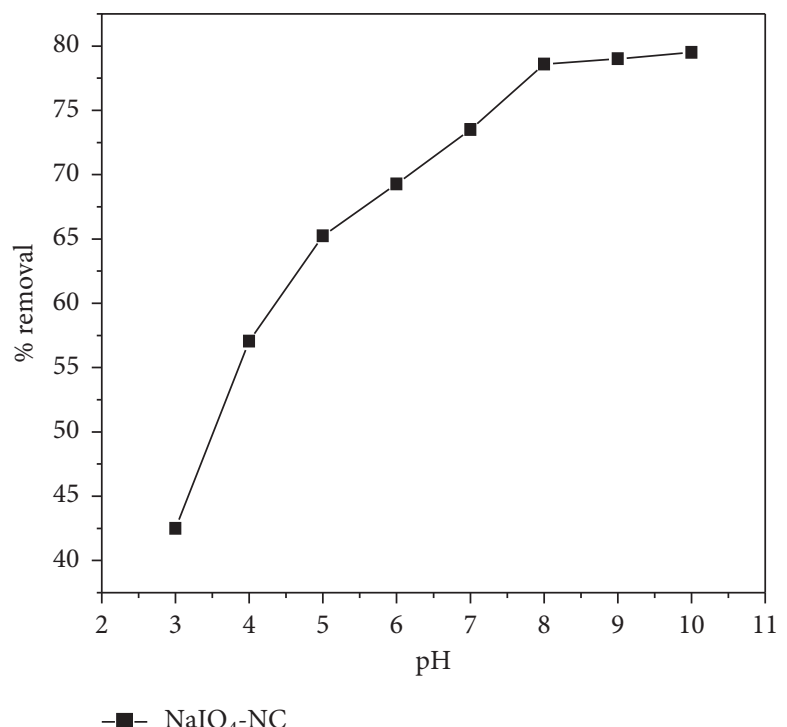

(c)

Figure 7: Effect of adsorbent dosage (a), PZC (b), and solution $\mathrm{pH}(\mathrm{c})$ on color removal using $\mathrm{NaIO}_{4}$ - $\mathrm{NC}$ adsorbent at optimum contact time of $60 \mathrm{~min}$., optimum temperature of $25^{\circ} \mathrm{C}$, and initial $\mathrm{MB}$ concentration of $30 \mathrm{mg} / \mathrm{L}$.

capability of the $\mathrm{NC}$ and $\mathrm{NaIO}_{4}-\mathrm{NC}$ sorbents, $n$ is the binding intensity, $T$ is the absolute temperature in Kelvin, $R$ is the ideal gas constant $\left(8.314 \mathrm{~J} \cdot \mathrm{mol}^{-1} \cdot \mathrm{K}^{-1}\right)$, and $K_{C}$ is the equilibrium constant calculated by multiplying the MB molar weight with Langmuir constant $(b)$.

3.5. Adsorption Kinetics. The adsorption kinetics of cationic $\mathrm{MB}$ dye by $\mathrm{NaIO}_{4}$-NC adsorbent was conducted using pseudo-first-order (PFO), pseudo second-order (PSO), and intraparticle diffusion given in the following equations, respectively, [60-62]:

$$
\begin{aligned}
\log \left(q_{e}-q_{t}\right) & =\log q_{e}-\frac{K_{1} t}{2.303} \\
\frac{t}{q_{t}} & =\frac{1}{K_{2} q_{e}{ }^{2}}+\frac{t}{q_{e}}, \\
Q_{t} & =k_{p} t^{0.5}+C_{i} .
\end{aligned}
$$

The parameters in relation to each kinetic uptake model were established considering their linear best fits (Figures 10(a)-10(c)). Table 3 indicates the correlation coefficient, $R^{2}$, and values of $0.887,0.998$, and 0.542 obtained by PFO, PSO, and intraparticle diffusion kinetic models, 


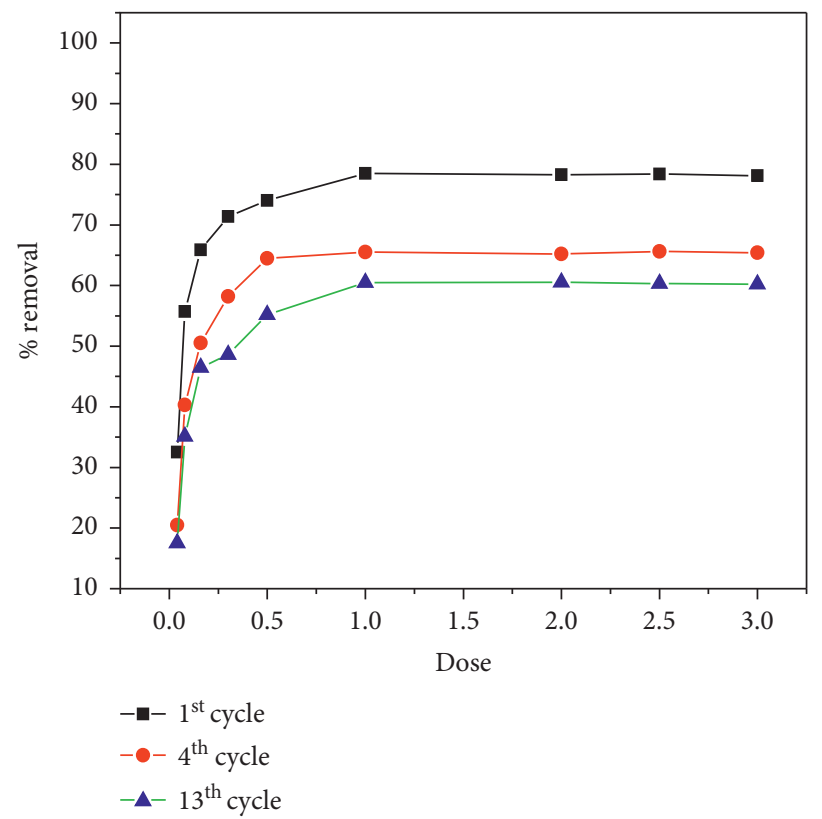

FIgURE 8: Percentage cationic MB dye removal after different cycles $\left(1^{\text {st }}, 4^{\text {th }}\right.$, and $\left.13^{\text {th }}\right)$ by $\mathrm{NaIO}_{4}$-NC sorbent.

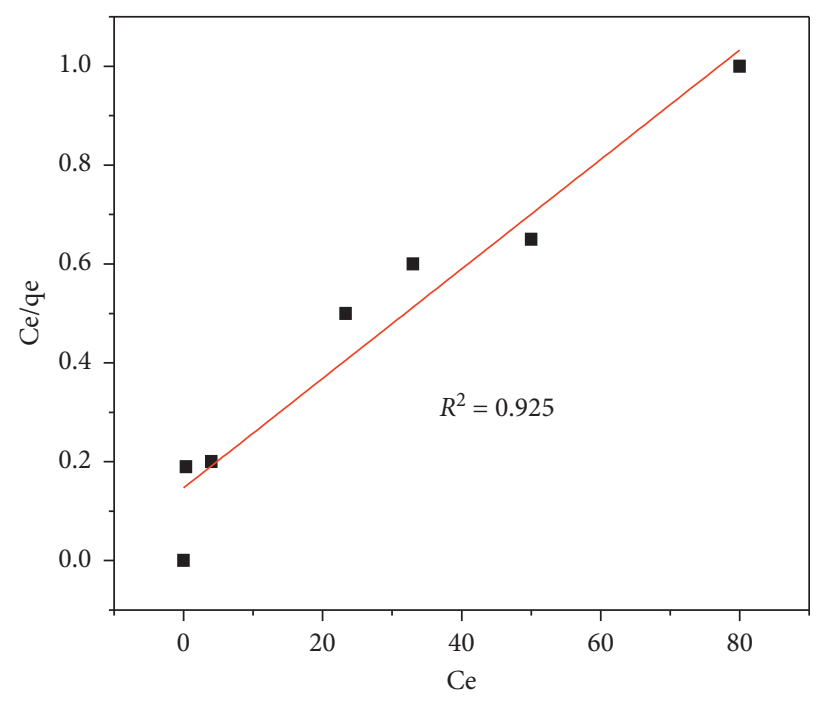

- $\mathrm{NaIO}_{4}-\mathrm{NC}$

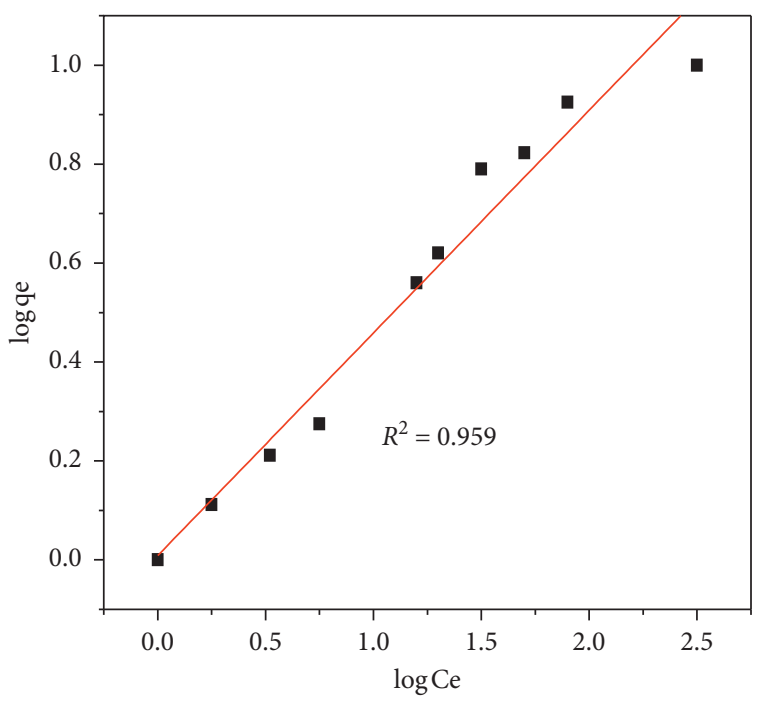

- $\mathrm{NaIO}_{4}-\mathrm{NC}$

(a)

(b)

Figure 9: Continued. 


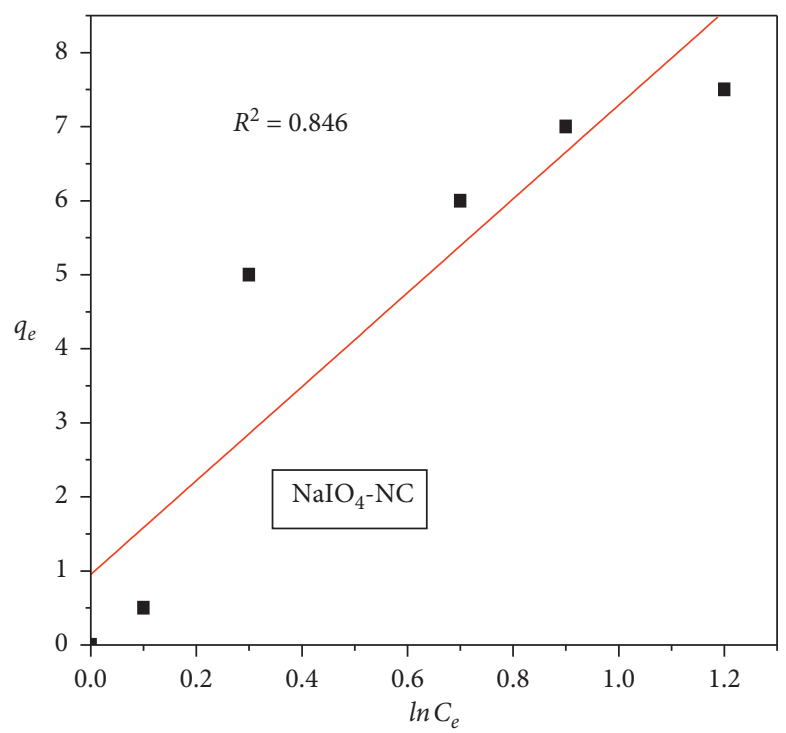

(c)

Figure 9: Langmuir (a), Freundlich (b), and Temkin (c) adsorption isotherm for the $\mathrm{MB}$ dye removal, respectively, at $C_{i}=30 \mathrm{mg} / \mathrm{L}, \mathrm{pH}=8$, adsorbent dose $=1 \mathrm{~g}$, and contact time $=60 \mathrm{~min}$.

TABLe 2: Langmuir and Freundlich isotherm constants for cationic MB dye uptake by $\mathrm{NC}$ and $\mathrm{NaIO}_{4}-\mathrm{NC}$ sorbent at $25^{\circ} \mathrm{C}$.

\begin{tabular}{lccccccccccc}
\hline \multirow{2}{*}{ Isotherm models } & \multicolumn{3}{c}{ Langmuir } & \multicolumn{4}{c}{ Freundlich } & \multicolumn{3}{c}{ Temkin } \\
& $Q_{\max }(\mathrm{mg} / \mathrm{g})$ & $b$ & $R_{L}$ & $R^{2}$ & $K_{f}$ & $n$ & $R^{2}$ & $\left(\Delta G^{\circ}\right)$ & $K_{T}$ & $B$ & $R^{2}$ \\
\hline $\mathrm{NaIO}_{4}$ - NC & 90.91 & 0.075 & 0.308 & 0.965 & 1.02 & 2.22 & 0.959 & -1.360 & 0.89 & 390.9 & 0.846 \\
\hline
\end{tabular}

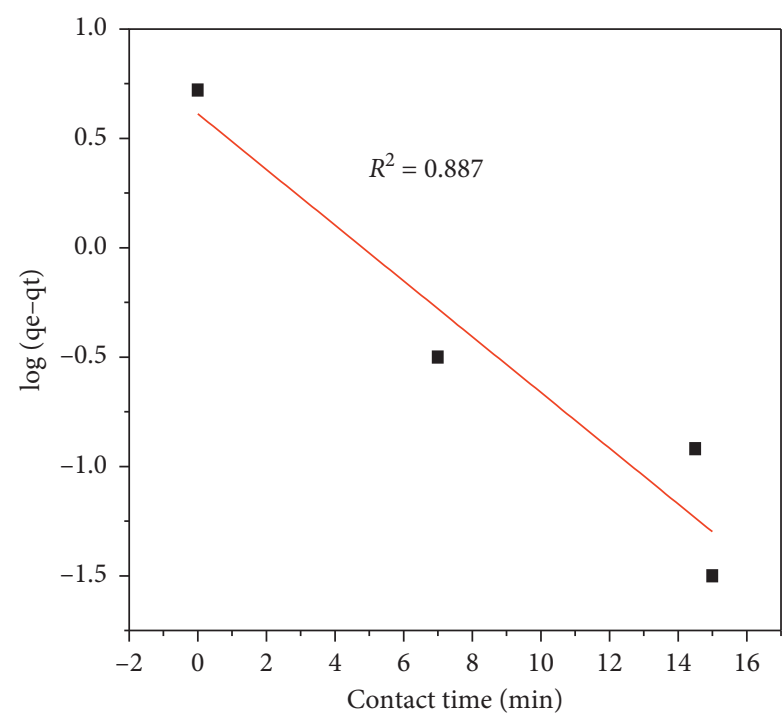

- $\mathrm{NaIO}_{4}-\mathrm{NC}$

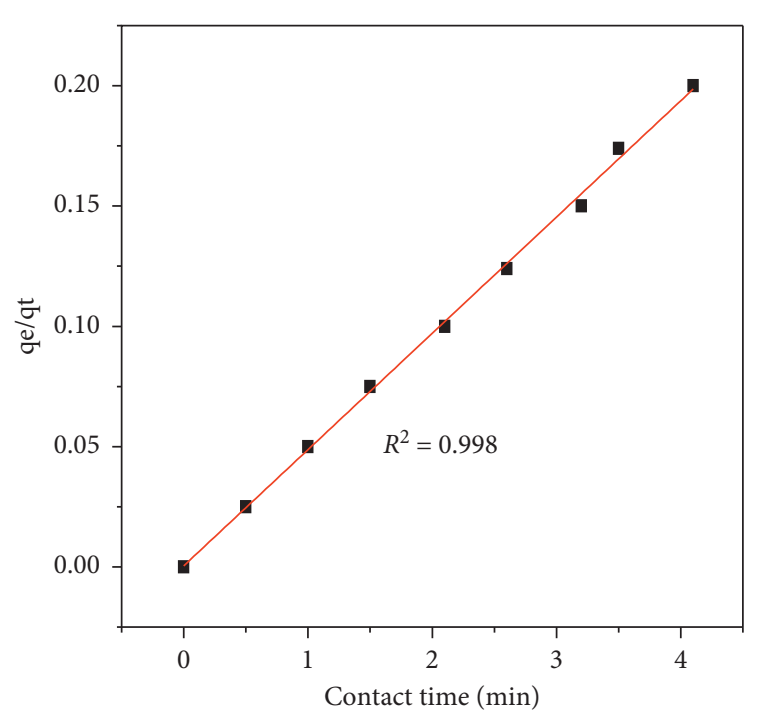

- $\mathrm{NaIO}_{4}-\mathrm{NC}$

(a)

(b)

FIgure 10: Continued. 


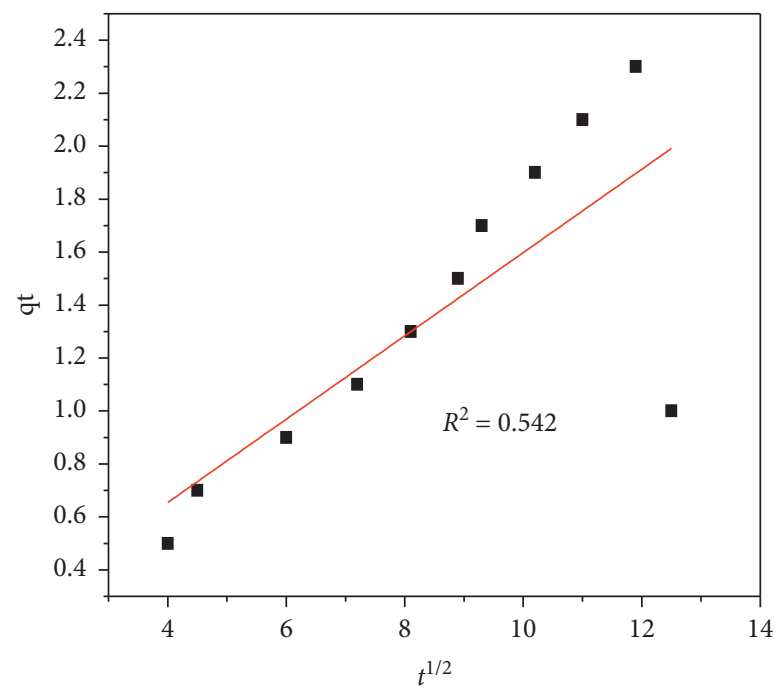

- $\mathrm{NaIO}_{4}-\mathrm{NC}$

(c)

Figure 10: Plots of the PFO (a), PSO (b), and intraparticle diffusion kinetics (c) model at $C_{i}=30 \mathrm{mg} / \mathrm{L}, \mathrm{pH}=8$, adsorbent dose $=1 \mathrm{~g}$, and contact time $=60 \mathrm{~min}$ for cationic $\mathrm{MB}$ dye removal, respectively.

TABle 3: The values of parameters and correlation coefficients of pseudo-second-order (PFO), pseudo-second-order (PSO), and intraparticle diffusion kinetics.

\begin{tabular}{|c|c|c|c|c|c|c|c|c|c|c|c|}
\hline \multirow[t]{2}{*}{ Kinetics } & \multicolumn{4}{|c|}{$\mathrm{PFO}$} & \multicolumn{4}{|c|}{$\mathrm{PSO}$} & \multicolumn{3}{|c|}{$\begin{array}{c}\text { Interparticle } \\
\text { diffusion }\end{array}$} \\
\hline & $q_{e}$. cal. $(\mathrm{mg} / \mathrm{g})$ & $q_{e}$. exp. $(\mathrm{mg} / \mathrm{g})$ & $K_{1}$ & $R^{2}$ & $q_{e}$. cal. $(\mathrm{mg} / \mathrm{g})$ & $q_{e}$ exp. $(\mathrm{mg} / \mathrm{g})$ & $K_{2}$ & $R^{2}$ & $K_{p}$ & $C_{i}$ & $R^{2}$ \\
\hline $\mathrm{NaIO}_{4}-\mathrm{NC}$ & 4.099 & 20.58 & 0.297 & 0.887 & 20.83 & 20.58 & 5.78 & 0.998 & 0.16 & 0.025 & 0.542 \\
\hline
\end{tabular}

respectively. The resultant $R^{2}$ of PSO kinetic model value approaches unity. This model offers the greater value of $q_{e}$ $\left(20.83 \mathrm{mg} \cdot \mathrm{g}^{-1}\right)$, compared to the PFO $q_{e}\left(4.099 \mathrm{mg} \cdot \mathrm{g}^{-1}\right)$, which is in disagreement with the value obtained experimentally $q_{e}\left(20.58 \mathrm{mg} \cdot \mathrm{g}^{-1}\right)$. According to $R^{2}$ values, the uptake of cationic $\mathrm{MB}$ dye on $\mathrm{NaIO}_{4}$-NC fits well with the PSO kinetic model. A similar result was previously reported for the uptake of $\mathrm{MB}$ on cellulose-based adsorbent Ma et al. [63].

3.6. Regeneration Test. Regeneration experiments were done to authenticate the reusability of the material for practical application in real systems. This experiment was achieved through desorption of the cationic MB dye from the adsorbent with the reaction of $\mathrm{HCl}$ solution with the adsorbate-loaded solution using batch experiments. The regenerated adsorbent was washed carefully with distilled water and dried. The dried adsorbent was subsequently reused as an adsorbent for at least 13 cycles. The results found that the uptake capability of cationic $\mathrm{MB}$ for $\mathrm{NaIO}_{4}{ }^{-}$ NC sorbent was progressively decreased with increasing cycles of reusable trials (Figure 8). The decrease in uptake capability of the sorbent with increased reusable times is ordinarily because of the loss of active sites on the surfaces of $\mathrm{NaIO}_{4}-\mathrm{NC}$ sorbent. The satisfied reusability with conserving basically extraordinary uptake ability for the $\mathrm{NaIO}_{4}-\mathrm{NC}$ sorbent postulates that the sorbent was effective in manipulating the uptake process of cationic MB dyes. Generally, it was found that the color removal ability of the $\mathrm{NaIO}_{4}-\mathrm{NC}$ sorbent did not suggestively change after the $13^{\text {th }}$ cycle of the procedure as the $\% R$ is still high. The $\% R$ for the 13 consecutive cycles was decreased below 5\%. On the whole, this confirms that $\mathrm{NaIO}_{4}-\mathrm{NC}$ can be used for contaminant uptake for a long time with an outstanding possibility. The results were in agreement with a study conducted by Kara et al. [64] on the modified cellulose nanomaterials (CNMs) for remediation of chromium (VI) ions from wastewater.

\section{Conclusion}

Sodium periodate modified nanocellulose $\left(\mathrm{NaIO}_{4}-\mathrm{NC}\right)$ adsorbent was a natural biodegradable and biocompatible, which is prepared from easily available and cheap lignocellulosic biomass by sulfuric hydrolysis methods. The prepared $\mathrm{NaIO}_{4}-\mathrm{NC}$ adsorbent was characterized using XRD, FTIR, SEM, and EDX characterization techniques. Next, it was applied for the removal of cationic MB dye from wastewater. Langmuir, Freundlich, and Temkin isotherm models fit well the experimental results. The high uptake capacity $\left(q_{\max }\right)$ is found to be $90.91 \mathrm{mg} \cdot \mathrm{g}^{-1}$. Also, $1 \mathrm{~g}$ of 
$\mathrm{NaIO}_{4}-\mathrm{NC}$ adsorbent was found to be the optimum amount of $\mathrm{NaIO}_{4}-\mathrm{NC}$ adsorbent to treat wastewater, containing $\mathrm{MB}$ as the main dye. PSO kinetic model was well-suited for the uptake of cationic MB by the force of electrostatic attraction between the negatively charged adsorbent surfaces and cationic MB dye. This suggests that the MB uptake processes follow chemisorption processes. In addition to the color removal, uptake by $\mathrm{NaIO}_{4}-\mathrm{NC}$ adsorbent decreases the physicochemical parameters of the WW. From the regeneration study, it is possible to conclude that the adsorbent was recyclable and applicable for 13 successive cycles without significant efficiency loss. Therefore, on the whole, the obtained results suggested that $\mathrm{NaIO}_{4}-\mathrm{NC}$ sorbent is an effective sorbent for the removal of cationic $\mathrm{MB}$ dye in particular and contaminants in general from the real WW.

\section{Data Availability}

The data implemented to support the results of the study are included within the manuscript.

\section{Conflicts of Interest}

The authors declare no conflicts of interest in terms of authorship and/or publication of this manuscript.

\section{Acknowledgments}

The authors acknowledge Adama Science and Technology University for providing funds and accommodations to do this work. This work has been funded by Project (ASTU, SoANS/JV-259298/2019), Research and Technology Transfer Office, Adama Science and Technology University.

\section{References}

[1] F. M. Chequer, G. A. Oliveira, E. A. Ferraz, J. C. Cardoso, M. V. Zanoni, and D. P. Olivera, Dyeing Process and Environmental Impact, Intech, London, UK, 2013.

[2] O. S. Ba, H. Ka, T. Shoe, H. Ya, and N. Yo, "Novel approach for effective removal of methylene blue dye from water using fava bean peel waste," Scientific Reports, vol. 7824, pp. 1-10, 2020.

[3] G. M. A. Al and R. S. Al Absi, "Mechanistic understanding of the adsorption and thermodynamic aspects of cationic methylene blue dye onto cellulosic olive stones biomass from wastewater," Scientific Reports, vol. 10, pp. 1-18, 2020.

[4] L.-F. Chen, H.-H. Wang, K.-Y. Lin, J.-Y. Kuo, M.-K. Wang, and C.-C. Liu, "Effective removal of methylene blue dye from water using three different low-cost adsorbents," Water Science and Technology, vol. 78, no. 3, pp. 556-570, 2018.

[5] L. Vutskits, A. Briner, P. Klauser et al., "Adverse effects of methylene blue on the central nervous system," Anesthesiology, vol. 108, no. 4, pp. 684-692, 2008.

[6] A. A. Alswat, M. B. Ahmad, and T. A. Saleh, "Zeolite modified with copper oxide and iron oxide for lead and arsenic adsorption from aqueous solutions," Journal of Water Supply: Research and Technology-Aqua, vol. 65, no. 6, pp. 465-479, 2016.

[7] Z. Heidarinejad, O. Rahmanian, M. Fazlzadeh, and M. Heidari, "Enhancement of methylene blue adsorption onto activated carbon prepared from date press cake by low frequency ultrasound," Journal of Molecular Liquids, vol. 264, pp. 591-599, 2018.

[8] M. T. Islam, H. Jing, T. Yang et al., "Fullerene stabilized gold nanoparticles supported on titanium dioxide for enhanced photocatalytic degradation of methyl orange and catalytic reduction of 4-nitrophenol," Journal of Environmental Chemical Engineering, vol. 6, no. 4, pp. 3827-3836, 2018.

[9] J. E. Padilla, J. Melendez, L. A. Barrera et al., "High dispersions of carbon nanotubes on cotton-cellulose benzoate fibers with enhanced electrochemical generation of reactive oxygen species in water," Journal of Environmental Chemical Engineering, vol. 6, no. 1, pp. 1027-1032, 2018.

[10] M. T. Islam, R. Saenz-Arana, H. Wang, R. Bernal, and J. C. Noveron, "Green synthesis of gold, silver, platinum, and palladium nanoparticles reduced and stabilized by sodium rhodizonate and their catalytic reduction of 4-nitrophenol and methyl orange," New Journal of Chemistry, vol. 42, no. 8, pp. 6472-6478, 2018.

[11] M. T. Islam, J. E. Padilla, N. Dominguez et al., "Green synthesis of gold nanoparticles reduced and stabilized by squaric acid and supported on cellulose fibers for the catalytic reduction of 4-nitrophenol in water," RSC Advances, vol. 6, no. 94, pp. 91185-91191, 2016.

[12] F. E. Titchou, R. A. Akbour, A. Assabbane, and M. Hamdani, "Removal of cationic dye from aqueous solution using Moroccan pozzolana as adsorbent: isotherms, kinetic studies, and application on real textile wastewater treatment," Groundwater For Sustainable Development, vol. 11, Article ID 100405, 2020.

[13] V. M. Matsis and H. P. Grigoropoulou, "Kinetics and equilibrium of dissolved oxygen adsorption on activated carbon," Chemical Engineering Science, vol. 63, no. 3, pp. 609-621, 2008.

[14] B. S. Mitchell, An Introduction to Materials Engineering and Science, John Wiley \& Sons, Hoboken, NJ, USA, 2004.

[15] A. M. Alansi, W. Z. Alkayali, M. H. Al-qunaibit, T. F. Qahtan, and T. A. Saleh, "Synthesis of exfoliated polystyrene/anionic clay MgAl-layered double hydroxide: structural and thermal properties," RSC Advances, vol. 5, no. 87, pp. 71441-71448, 2015.

[16] K. B. Tan, M. Vakili, B. A. Horri, P. E. Poh, A. Z. Abdullah, and B. Salamatinia, "Adsorption of dyes by nanomaterials: recent developments and adsorption mechanisms," Separation and Purification Technology, vol. 150, pp. 229-242, 2015.

[17] Q. Lin, K. Wang, M. Gao, Y. Bai, L. Chen, and H. Ma, "Effectively removal of cationic and anionic dyes by $\mathrm{pH}$ sensitive amphoteric adsorbent derived from agricultural waste-wheat straw," Journal of the Taiwan Institute of Chemical Engineers, vol. 76, pp. 65-72, 2017.

[18] H. T. Kara, S. T. Anshebo, and F. K. Sabir, "Preparation and characterization of functionalized cellulose nanomaterials (CNMs) for $\mathrm{Pb}$ (II) ions removal from wastewater," Journal of Chemistry, vol. 2021, Article ID 5514853, 18 pages, 2021.

[19] J. N. Putro, S. P. Santoso, F. E. Soetaredjo, S. Ismadji, and Y.-H. Ju, "Nanocrystalline cellulose from waste paper: adsorbent for azo dyes removal," Environmental Nanotechnology, Monitoring \& Management, vol. 12, Article ID 100260, 2019.

[20] Y. Tang, T. Lin, C. Jiang, Y. Zhao, and S. Ai, "Renewable adsorbents from carboxylate-modified agro-forestry residues for efficient removal of methylene blue dye," Journal of Physics and Chemistry of Solids, vol. 149, Article ID 109811, 2021.

[21] P. Duolikun, T. Pynadathu, N. Moosavi et al., "Comprehensive review on nanocellulose: recent developments, 
challenges and future prospects," Journal of the Mechanical Behavior of Biomedical Materials, vol. 110, Article ID 103884, 2020.

[22] H. Qiao, Y. Zhou, F. Yu et al., "Effective removal of cationic dyes using carboxylate-functionalized cellulose nanocrystals," Chemosphere, vol. 141, pp. 297-303, 2015.

[23] K. B. Tan, K. Bing, A. Kifait, A. Zuhairi, and B. Amini, "Development of self-assembled nanocrystalline cellulose as a promising practical adsorbent for methylene blue removal," Carbohydrate Polymers, vol. 199, pp. 92-101, 2018.

[24] J. Shojaeiarani, D. S. Bajwa, and K. Hartman, "Esterified cellulose nanocrystals as reinforcement in poly (lactic acid) nanocomposites," Cellulose, vol. 26, no. 4, pp. 2349-2362, 2019.

[25] S. Desseaux, S. Dos Santos, T. Geiger et al., "Improved mechanical properties of bitumen modified with acetylated cellulose fibers," Composites Part B: Engineering, vol. 140, pp. 139-144, 2018.

[26] S. Nie, K. Zhang, X. Lin et al., "Enzymatic pretreatment for the improvement of dispersion and film properties of cellulose nanofibrils," Carbohydrate Polymers, vol. 181, pp. 1136-1142, 2018.

[27] B. P. Frank, D. P. Durkin, E. R. Caudill et al., "Impact of silanization on the structure, dispersion properties, and biodegradability of nanocellulose as a nanocomposite filler," ACS Applied Nano Materials, vol. 1, no. 12, pp. 7025-7038, 2018.

[28] A. Potthast, S. Schiehser, T. Rosenau, and M. Kostic, "Oxidative modifications of cellulose in the periodate system-reduction and beta-elimination reactions," Holzforschung, vol. 63, no. 1, pp. 25-29, 2009.

[29] Y. Jiang, J. Zhou, Z. Yang et al., "Dialdehyde cellulose nanocrystal/gelatin hydrogel optimized for 3D printing applications," Journal of Materials Science, vol. 53, no. 16, pp. 11883-11900, 2018.

[30] H. Zazou, H. Afanga, S. Akhouairi et al., "Treatment of textile industry wastewater by electrocoagulation coupled with electrochemical advanced oxidation process," Journal of Water Process Engineering, vol. 28, pp. 214-221, 2019.

[31] H. Afanga, H. Zazou, F. E. Titchou et al., "Integrated electrochemical processes for textile industry wastewater treatment: system performances and sludge settling characteristics," Sustainable Environment Research, vol. 30, no. 1, p. 2, 2020.

[32] X. Xu, Y. Long, Q. Li et al., "Modified cellulose membrane with good durability for effective oil-in-water emulsion treatment," Journal of Cleaner Production, vol. 211, pp. 1463-1470, 2019.

[33] M. Asrofi, H. Abral, A. Kasim, A. Pratoto, M. Mahardika, and F. Hafizulhaq, "Characterization of the sonicated yam bean starch bionanocomposites reinforced by nanocellulose water hyacinth fiber (WHF): the effect of various fiber loading," Journal of Engineering Science and Technology, vol. 13, pp. 2700-2715, 2018.

[34] M. Asrofi, H. Abral, Y. K. Putra, S. Sapuan, and H.-J. Kim, "Effect of duration of sonication during gelatinization on properties of tapioca starch water hyacinth fiber biocomposite," International Journal of Biological Macromolecules, vol. 108, pp. 167-176, 2018.

[35] M. Asrofi, H. Abral, A. Kasim et al., "Isolation of nanocellulose from water hyacinth fiber (WHF) produced via digester-sonication and its characterization," Fibers and Polymers, vol. 19, no. 8, pp. 1618-1625, 2018.
[36] E. Syafri, S. Jamaluddin, S. Wahono et al., "Characterization and properties of cellulose microfibers from water hyacinth filled sago starch biocomposites," International Journal of Biological Macromolecules, vol. 137, pp. 119-125, 2019.

[37] N. Dordevic, A. D. Marinkovic, J. B. Nikolic et al., "A study of the barrier properties of polyethylene coated with a nanocellulose/magnetite composite film," Journal of the Serbian Chemical Society, vol. 81, no. 5, pp. 589-605, 2016.

[38] J. Chen, H. Kong, D. Wu, X. Chen, D. Zhang, and Z. Sun, "Phosphate immobilization from aqueous solution by fly ashes in relation to their composition," Journal of Hazardous Materials, vol. 139, no. 2, pp. 293-300, 2007.

[39] E. I. Unuabonah, K. O. Adebowale, and B. I. Olu-Owolabi, "Kinetic and thermodynamic studies of the adsorption of lead (II) ions onto phosphate-modified kaolinite clay," Journal of Hazardous Materials, vol. 144, no. 1-2, pp. 386-395, 2007.

[40] G. J. Vadakkekara, S. Thomas, and C. P. R. Nair, "Maleic acid modified cellulose for scavenging lead from water," International Journal of Biological Macromolecules, vol. 129, pp. 293-304, 2019.

[41] D. Gaspar, S. N. Fernandes, A. G. De Oliveira et al., "Nanocrystalline cellulose applied simultaneously as the gate dielectric and the substrate in flexible field effect transistors," Nanotechnology, vol. 25, no. 9, Article ID 094008, 2014.

[42] M. Thommes, K. Kaneko, A. V. Neimark et al., "Physisorption of gases, with special reference to the evaluation of surface area and pore size distribution (IUPAC Technical Report)," Pure and Applied Chemistry, vol. 87, no. 9, pp. 1051-1069, 2015.

[43] E. R. Cohen, I. Mills, H. L. Strauss et al., "Quantities, units and symbols in physical chemistry," International Union of Pure and Applied Chemistry, vol. 233, 2007.

[44] E. Igberase, A. Ofomaja, and P. O. Osifo, "Enhanced heavy metal ions adsorption by 4 -aminobenzoic acid grafted on chitosan/epichlorohydrin composite: kinetics, isotherms, thermodynamics and desorption studies," International Journal of Biological Macromolecules, vol. 123, pp. 664-676, 2019.

[45] M. Munir, M. F. Nazar, M. N. Zafar et al., "Effective adsorptive removal of methylene blue from water by didodecyldimethylammonium bromide-modified Brown clay," ACS Omega, vol. 5, no. 27, pp. 16711-16721, 2020.

[46] V. K. Gupta, R. Jain, A. Mittal et al., "Photo-catalytic degradation of toxic dye amaranth on $\mathrm{TiO} 2 / \mathrm{UV}$ in aqueous suspensions," Materials Science and Engineering: C, vol. 32, no. 1, pp. 12-17, 2012.

[47] M. R. Gopal Reddi, T. Gomathi, M. Saranya, and P. N. Sudha, "Adsorption and kinetic studies on the removal of chromium and copper onto Chitosan-g-maliec anhydride-g-ethylene dimethacrylate," International Journal of Biological Macromolecules, vol. 104, pp. 1578-1585, 2017.

[48] J. Sun, Y. Chen, H. Yu, L. Yan, B. Du, and Z. Pei, "Removal of $\mathrm{Cu}^{2+}, \mathrm{Cd}^{2+}$ and $\mathrm{Pb}^{2+}$ from aqueous solutions by magnetic alginate microsphere based on $\mathrm{Fe}_{3} \mathrm{O}_{4} / \mathrm{MgAl}$-layered double hydroxide," Journal of Colloid and Interface Science, vol. 532, pp. 474-484, 2018.

[49] S. Ben-Ali, I. Jaouali, S. Souissi-Najar, and A. Ouederni, "Characterization and adsorption capacity of raw pomegranate peel biosorbent for copper removal," Journal of Cleaner Production, vol. 142, pp. 3809-3821, 2017.

[50] A. Salama, H. A. Aljohani, and K. R. Shoueir, "Oxidized cellulose reinforced silica gel: New hybrid for dye adsorption," Materials Letters, vol. 230, pp. 293-296, 2018. 
[51] D. Li, J. Li, Q. Gu, S. Song, and C. Peng, "Co-influence of the pore size of adsorbents and the structure of adsorbates on adsorption of dyes," Desalination and Water Treatment, vol. 57, no. 31, pp. 14686-14695, 2016.

[52] I. Ali, O. M. L. Alharbi, Z. A. Alothman, A. Y. Badjah, A. Alwarthan, and A. A. Basheer, "Artificial neural network modelling of amido black dye sorption on iron composite nano material: kinetics and thermodynamics studies," Journal of Molecular Liquids, vol. 250, pp. 1-8, 2018.

[53] R. Ezzati, "Derivation of pseudo-first-order, pseudo-secondorder and modified pseudo-first-order rate equations from Langmuir and Freundlich isotherms for adsorption," Chemical Engineering Journal, vol. 392, Article ID 123705, 2020.

[54] W.-C. Qian, X.-P. Luo, X. Wang, M. Guo, and B. Li, "Removal of methylene blue from aqueous solution by modified bamboo hydrochar," Ecotoxicology and Environmental Safety, vol. 157, pp. 300-306, 2018.

[55] A. Dbik, S. Bentahar, M. El Khomri, N. El Messaoudi, and A. Lacherai, "Adsorption of Congo red dye from aqueous solutions using tunics of the corm of the saffron," Materials Today: Proceedings, vol. 22, pp. 134-139, 2020.

[56] I. Langmuir, "The adsorption of gases on plane surfaces of glass, mica and platinum," Journal of the American Chemical Society, vol. 40, no. 9, pp. 1361-1403, 1918.

[57] K. R. Hall, L. C. Eagleton, A. Acrivos, and T. Vermeulen, "Pore- and solid-diffusion kinetics in fixed-bed adsorption under constant-pattern conditions," Industrial \& Engineering Chemistry Fundamentals, vol. 5, pp. 212-223, 1966.

[58] H. Freundlich, "Over the adsorption in solution," Journal of Physical Chemistry, vol. 57, pp. 1100-1107, 1906.

[59] M. Temkin and V. Pyzhev, "Kinetics of ammonia synthesis on promoted iron catalysts," Acta Physiochim. URSS, vol. 12, pp. 327-356, 1940.

[60] O. Hamdaoui and M. Chiha, "Removal of methylene blue from aqueous solutions by wheat bran," Acta Chimica Slovenica, vol. 54, pp. 407-418, 2007.

[61] Y. S. Ho and G. McKay, "Kinetic models for the sorption of from aqueous solution by wood," Journal of Environmental Science Health Part B: Process Safety and Environmental Protection, vol. 76, pp. 183-191, 1998.

[62] M. Dogan, H. Abak, and M. Alkan, "Adsorption of methylene blue onto hazelnut shell: kinetics, mechanism and activation parameters," Journal of Hazardous Materials, vol. 164, no. 1, pp. 172-181, 2009.

[63] M. Ma, Y. Chen, X. Zhao et al., "Effective removal of cation dyes from aqueous solution using robust cellulose sponge," Journal of Saudi Chemical Society, vol. 24, pp. 915-924, 2020.

[64] H. T. Kara, S. T. Anshebo, and F. K. Sabir, "A novel modified cellulose nanomaterials (CNMs) for remediation of chromium (VI) ions from wastewater," Materials Research Express, vol. 7, 2020. 